\title{
The Bacterial Species
} \section{Campylobacter jejuni Induce Diverse Innate Immune Responses in Human and Avian Intestinal Epithelial Cells}

\section{Daniel A. John ${ }^{1}$, Lisa K. Williams ${ }^{1}$, Venkateswarlu Kanamarlapudi ${ }^{1,2}$, Thomas J. Humphrey ${ }^{1}$ and Thomas S. Wilkinson ${ }^{1 *}$}

1 Microbiology and Infectious Disease, Swansea University Medical School, Institute of Life Science, Swansea University, Swansea, United Kingdom, ${ }^{2}$ Cellular Biology, Swansea University Medical School, Institute of Life Science, Swansea University, Swansea, United Kingdom

Campylobacter remain the major cause of human gastroenteritis in the Developed World causing a significant burden to health services. Campylobacter are pathogens in humans and chickens, although differences in mechanistic understanding are incomplete, in part because phenotypic strain diversity creates inconsistent findings. Here, we took Campylobacter jejuni isolates $(n=100)$ from multi-locus sequence typed collections to assess their pathogenic diversity, through their inflammatory, cytotoxicity, adhesion, invasion and signaling responses in a high-throughput model using avian and human intestinal epithelial cells. C. jejuni induced IL-8 and CXCLi1/2 in human and avian epithelial cells, respectively, in a MAP kinase-dependent manner. In contrast, $\mathrm{IL}-10$ responses in both cell types were PI 3-kinase/Akt-dependent. C. jejuni strains showed diverse levels of invasion with high invasion dependent on MAP kinase signaling in both cell lines. C. jejuni induced diverse cytotoxic responses in both cell lines with cdt-positive isolates showing significantly higher toxicity. Blockade of endocytic pathways suggested that invasion by $C$. jejuni was clathrin- and dynamin-dependent but caveolae- independent in both cells. In contrast, IL-8 (and CXCLi1/2) production was dependent on clathrin, dynamin, and caveolae. This study is important because of its scale, and the data produced, suggesting that avian and human epithelial cells use similar innate immune pathways where the magnitude of the response is determined by the phenotypic diversity of the Campylobacter species.

Keywords: Campylobacter jejuni, human and avian epithelial cells, IL-8, CXCLi1/CXCLi2, invasion, signaling, endocytosis

\section{INTRODUCTION}

Campylobacter is a leading cause of bacterial food-borne diarrhoeal disease worldwide, with symptoms ranging from mild to serious infections, which can result in permanent neurological damage; especially in elderly people (Silva et al., 2011). It is frequently found in poultry and chicken is an important source of Campylobacter infection. In the United Kingdom alone, Campylobacter is estimated to cause up to 700000 cases of infection and more than 100 deaths each year. Campylobacter infection costs the United Kingdom economy at least $£ 900$ million per year (DEFRA, 2012). In addition, Campylobacter jejuni is the most common species to cause a rare neuromuscular paralysis known as Guillain-Barré syndrome (Parkhill et al., 2000). 
Campylobacter jejuni is pathogenic in humans and avian hosts although mechanistic understanding of differences is incomplete (Byrne et al., 2007; Jennings et al., 2011; Williams et al., 2013; Humphrey et al., 2014). Despite this and in limited isolates (such as M1, NCTC 11168, 13126, NCTC 12744) strain dependency is particularly well documented. Thus, individual C. jejuni genotypes have been shown to produce their own unique infection rates and in vivo behaviors in chickens when taken from the two major MLST clonal complexes (CC), CC-45 and CC-21 (Chaloner et al., 2014). This heterogeneity has also identified strains with an invasive phenotype that lead to extra-intestinal spread (Humphrey et al., 2015), and have been implicated in recent outbreaks (Harrison et al., 2013; Edwards et al., 2014). However, the differences between C. jejuni strains which cause invasive disease and those which remain localized in the gut are poorly understood. One recent explanation suggests that dysregulation of cytokine production leading to an overexuberant pro-inflammatory response leads to gut damage and bacterial invasion (Humphrey et al., 2014). However, there is a relative paucity of data regarding the ability of individual C. jejuni, across the wide spectrum of different strains, to cause inflammation.

Genes important for C. jejuni virulence are associated with motility, adhesion, invasion and toxin production (Table 1). C. jejuni is a highly motile organism with bipolar flagella and motility is very important for colonization and infection in chickens and other animals (Guerry, 2007). Genes involved in motility include $f l a A, f l a B$, and $f l a C$. The flaA gene is also important for invasion of epithelial cells, and is responsible for adherence and colonization by $C$. jejuni in the gastrointestinal tract (Guerry, 2007). In addition, flagella may help C. jejuni invasion mechanisms by serving as export apparatus in the secretion of non-flagellar proteins (Konkel et al., 2004), including the ability to deliver flaC and Campylobacter invasion antigen (cia) into the cell's cytoplasm (Konkel et al., 2004). CiaC is required for bacterial invasion into host cells whereas ciaI has been reported to be required for intracellular survival of C. jejuni after invasion (Buelow et al., 2011; Eucker and Konkel, 2012). The 'invasion associated protein' is encoded by iam $A$ and its exact role in this process is still unclear (Rivera-Amill et al., 2001). HtrA, a serine protease, may act as a chaperone protein, which affects folding of adhesins (Bæk et al., 2011). One of the main toxins produced by $C$. jejuni is cytolethal distending toxin (CDT), which causes direct DNA damage leading to the activation of DNA damage checkpoint pathways, resulting in cell death (Lee et al., 2003). CDT consists of three protein subunits (CdtA, CdtB, and CdtC), which are encoded by genes $c d t A, c d t B$, and $c d t C$. The expression of all three genes is required in order to produce an active form of CDT (Pickett et al., 1996).

Understanding the mechanisms behind Campylobacter interaction with the host has focussed attention on human intestinal epithelial cells (e.g., HT-29, T84, and CaCo-2) and has shown that bacterial internalization is very important in C. jejuni pathogenesis (Jin et al., 2003; MacCallum et al., 2006; Byrne et al., 2007; Larson et al., 2008; Friis et al., 2009; Li et al., 2011). C. jejuni invades intestinal epithelial cells in a microtubule-, microfilament- and caveolin-dependent manner with a distinct cell type specificity (Oelschlaeger et al., 1993; Byrne et al., 2007; Larson et al., 2008; Watson and Galán, 2008). Invasion of human intestinal epithelial cells by C. jejuni activates numerous downstream signaling pathways, including the MAP kinases, ERK and p38, leading to the production of the pro-inflammatory cytokine interleukin-8 (IL-8) (Hickey et al., 2000; Jin et al., 2003; Li et al., 2011) and the anti-inflammatory cytokine IL-10 in human systems (Li et al., 2011). Indeed, a relationship between IL-8 production and C. jejuni invasion has been previously proposed in human cells (Li et al., 2016). Whether similar responses are observed in avian epithelial cells is poorly understood and is complicated by the presence of two IL-8 orthologs, IL-8like1 (CXCLi1) and IL-8like2 (CXCLi2), which are both induced by Campylobacter (Larson et al., 2008).

No studies have investigated whether similar mechanisms exist across collections of C. jejuni strains that define the species and have been isolated from relevant environmental, veterinary or clinical sources. In addition, previous work alluded to above in human cells, and the very limited work in chicken epithelial cells, do not represent the diversity across the Campylobacter species ( $<8$ strains). In this work, we investigated the response of 100 C. jejuni strains that have been characterized previously at the genome level (Sheppard et al., 2013) by investigating their inflammatory (cytokine), adhesion, invasion, toxicity and signalling responses in $8 \mathrm{E} 11$ (avian) intestinal epithelial cells and compared these responses with human intestinal epithelial cells (HT-29). The host responses measured here suggest that avian and human epithelial cells share common mechanisms to combat C. jejuni but there is exceptional phenotypic diversity in the bacterial population.

\section{MATERIALS AND METHODS}

\section{Bacterial Strains, Genomes, and Culture Conditions}

A collection of 100 fully sequenced isolates of C. jejuni from a variety of sources and sequence types were used in this study and had been characterized previously at the genomic level (Sheppard et al., 2011, 2013) (Figure 1 and Table 2). In brief, sequences were annotated using Prokka (Seemann, 2014). The resulting assemblies were used for calculations in Roary (Page et al., 2015) to create a pan-genome. Then, MEGA 6 (Tamura et al., 2013) was used to visualize the resulting data on a phylogenetic tree. C. jejuni strains were cultured under microaerobic conditions $\left(5 \% \mathrm{O}_{2}, 10 \% \mathrm{CO}_{2}, 85 \% \mathrm{~N}_{2}\right)$ on Campylobacter blood free selective medium (mCCDA; Oxoid) plates at $42^{\circ} \mathrm{C}$ (Davis and DiRita, 2008). One colony of cultured C. jejuni was then inoculated into Muller-Hinton ( $\mathrm{MH}$ ) broth and grown for $24 \mathrm{~h}$ at $42^{\circ} \mathrm{C}$ before being used in downstream assays.

\section{Motility Assays}

Two milliliters of $\mathrm{MH}$ medium supplemented with $0.4 \%$ agar was aliquoted to each well of a 6-well plate and allowed to solidify. Then, $2 \mu \mathrm{l}$ of $C$. jejuni suspensions $\left(0.1 \mathrm{OD}_{600}\right)$ were added to the center of a well, and the plate incubated at $37^{\circ} \mathrm{C}$ under microaerobic conditions for $48 \mathrm{~h}$. Relative motility of each 
TABLE 1 | Presence and absence of important virulence factors in Campylobacter jejuni isolates used in this study.

\begin{tabular}{|c|c|c|}
\hline Gene & Presence \% & Absence \% \\
\hline \multicolumn{3}{|l|}{ Motility } \\
\hline flaA/flaB & 28.95 & 71.05 \\
\hline $\mathrm{flaC}$ & 96.72 & 3.28 \\
\hline flgs & 95.39 & 4.61 \\
\hline $\mathrm{flgR}$ & 95.39 & 4.61 \\
\hline fliA & 96.72 & 3.28 \\
\hline \multicolumn{3}{|c|}{ Adhesion } \\
\hline cadF & 96.72 & 3.28 \\
\hline pldA & 93.42 & 6.58 \\
\hline peb1A & 97.36 & 2.64 \\
\hline peb3 & 82.23 & 17.77 \\
\hline peb4 & 96.05 & 3.95 \\
\hline \multicolumn{3}{|c|}{ Invasion } \\
\hline ciaB & 94.07 & 5.93 \\
\hline htrA & 97.37 & 2.63 \\
\hline iamA & 96.05 & 3.95 \\
\hline iamB & 96.71 & 3.29 \\
\hline \multicolumn{3}{|l|}{ Toxicity } \\
\hline cdtA & 86.85 & 13.15 \\
\hline cdtB & 91.45 & 8.55 \\
\hline cdtC & 88.82 & 11.18 \\
\hline \multicolumn{3}{|l|}{ Misc } \\
\hline porA & 96.05 & 3.95 \\
\hline $\mathrm{fCl}$ & 48.68 & 51.32 \\
\hline hddC & 14.47 & 85.53 \\
\hline $\mathrm{rfbC}$ & 51.97 & 48.03 \\
\hline cj0794 & 65.78 & 34.22 \\
\hline cj0859c & 46.71 & 53.29 \\
\hline
\end{tabular}

bacterial strain was determined by measuring the diameter of the migration zone.

\section{Growth Assays}

Campylobacter jejuni growth was measured using a semiquantitative assay in Nunc 96-well tissue culture plates (Pascoe et al., 2015). Briefly, C. jejuni strains were grown overnight in $\mathrm{MH}$ liquid medium at $37^{\circ} \mathrm{C}$ under microaerobic conditions $(5 \%$ $\mathrm{O}_{2}, 10 \% \mathrm{CO}_{2}, 85 \% \mathrm{~N}_{2}$ ) and diluted using $\mathrm{MH}$ to $0.1 \mathrm{OD}_{600}$. Five microlitres of the diluted bacterial suspension were inoculated into $200 \mu \mathrm{l}$ of fresh $\mathrm{MH}$ and bacterial growth monitored in real-time over $48 \mathrm{~h}$ at 37 and $42^{\circ} \mathrm{C}$ in a FLUOstar OMEGA plate reader (BMG LabTech, Bucks United Kingdom) equipped with an atmospheric control unit to maintain a microaerobic atmosphere $\left(5 \% \mathrm{O}_{2}, 10 \% \mathrm{CO}_{2}, 85 \% \mathrm{~N}_{2}\right)$. Spectrophotometric measurements were taken at $\mathrm{OD}_{600}$ every $60 \mathrm{~min}$ and the average of at least three replicates was calculated.

\section{Culture of Human and Chicken Epithelial Cells}

Human colon epithelial adenocarcinoma cells (HT-29) were grown in McCoy's 5A (Modified) medium supplemented with L-glutamine (5 mM), Penicillin (10,000 U/ml), Streptomycin

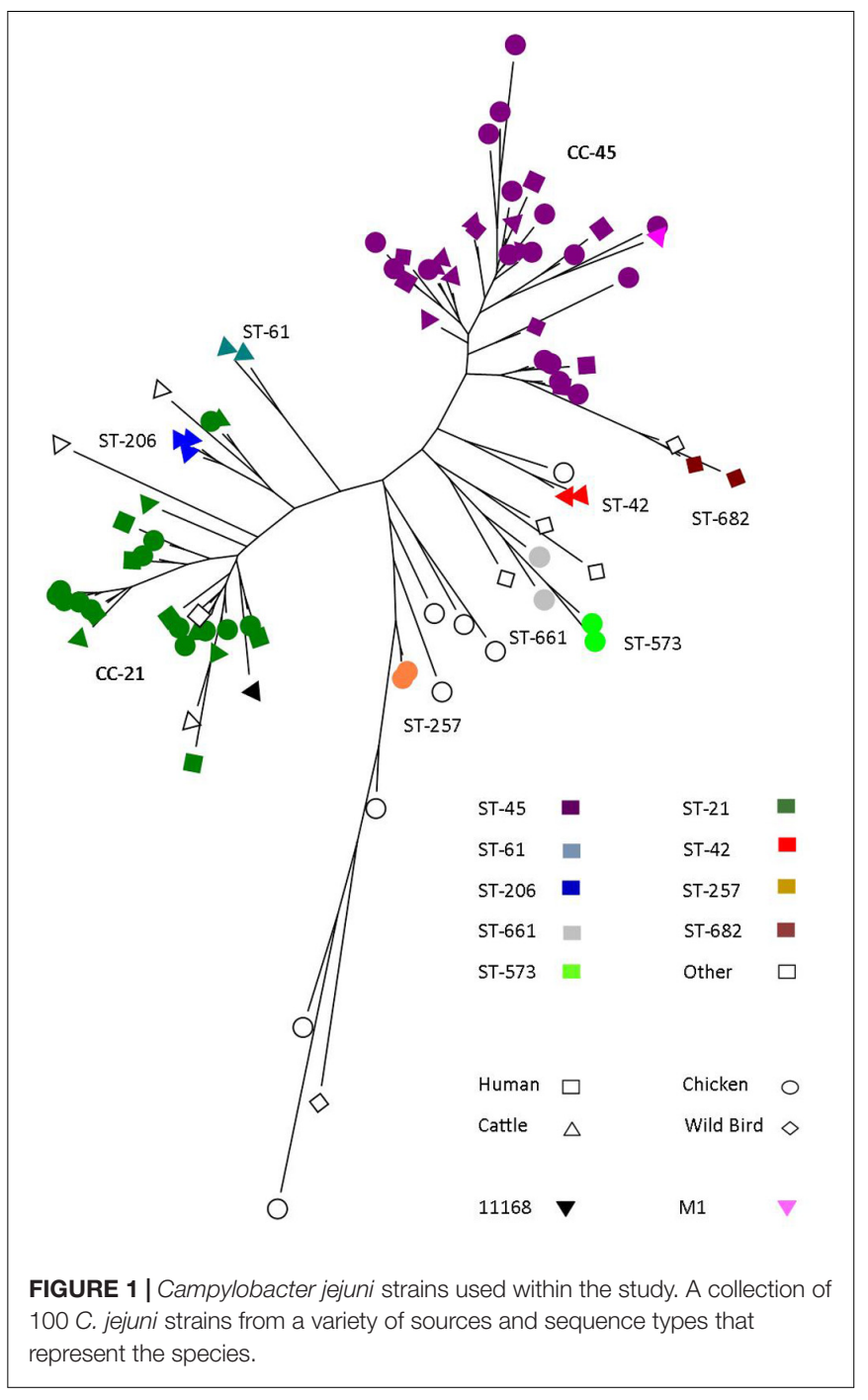

$(10,000 \mathrm{U} / \mathrm{ml})(\mathrm{G} / \mathrm{P} / \mathrm{S})$ and $10 \%$ foetal bovine serum (FBS). Chicken epithelial cells (MM-CHiC clone, 8E11 (Micromol, Germany) were maintained in Dulbecco's modified eagle medium/nutrient mixture F-12 (DMEM/F-12) with G/P/S and $10 \%$ FBS. Cultures were maintained in $\mathrm{T} 75$ flasks at $37^{\circ} \mathrm{C}$ in a $5 \% \mathrm{CO}_{2}$ incubator.

\section{Epithelial Cell Viability Assay}

This was assessed using the AlamarBlue Reagent (Thermo Fisher Scientific) according to manufacturer's instructions. AlamarBlue cell viability reagent functions as a cell health indicator using the reducing power of living cells. Viable cells are able to continuously convert resazurin, the active ingredient in alamarblue, to resorufin and so increasing the overall fluorescence and color of the media. Results are presented as a percentage reduction in cell viability. Briefly; $5 \mu l$ of AlamarBlue reagent was added to each well of a 96-well plate containing HT-29 or 8E11 cells infected with C. jejuni in $50 \mu \mathrm{l}$ of conditioned medium. Plates were incubated for $4 \mathrm{~h}$ at $37^{\circ} \mathrm{C}$ and absorbance was measured at $\mathrm{OD}_{570}$, and $\mathrm{OD}_{600}$. 
TABLE 2 | List of 100 strains used in this study.

\begin{tabular}{|c|c|c|c|c|}
\hline Isolate & Species & Clonal complex & Source & IL-8 \\
\hline CAMP45 & C. jejuni & ST-45 & Chicken & \\
\hline CAMP61 & C. jejuni & ST-61 & Cattle & \\
\hline CampsClin11 & C. jejuni & ST-45 & Human & High \\
\hline CampsClin45 & C. jejuni & ST-45 & Human & High \\
\hline CampsClin262 & C. jejuni & ST-21 & Human & \\
\hline CampsClin583 & C. jejuni & ST-45 & Human & High \\
\hline CampsClin266 & C. jejuni & ST-21 & Human & \\
\hline CampsClin883 & C. jejuni & ST-21 & Human & High \\
\hline CampsClin1003 & C. jejuni & ST-45 & Human & \\
\hline Chick2219 & C. jejuni & ST-45 & Chicken & \\
\hline Chicka21 & C. jejuni & ST-21 & Chicken & \\
\hline Cow55 & C. jejuni & - & Cattle & \\
\hline Cow42 & C. jejuni & ST-42 & Cattle & \\
\hline Chick2253 & C. jejuni & - & Chicken & \\
\hline Chick594 & C. jejuni & ST-45 & Chicken & \\
\hline Cow2673 & C. jejuni & - & Cattle & \\
\hline Cow2674 & C. jejuni & ST-21 & Cattle & \\
\hline Cow206 & C. jejuni & ST-206 & Cattle & \\
\hline Cow38 & C. jejuni & ST-48 & Cattle & \\
\hline Cow190 & C. jejuni & - & Cattle & \\
\hline Cow334 & C. jejuni & ST-45 & Cattle & \\
\hline Chicka45 & C. jejuni & - & Chicken & \\
\hline Chick267 & C. jejuni & ST-283 & Chicken & \\
\hline CampsClin230 & C. jejuni & ST-45 & Human & \\
\hline Cowa45 & C. jejuni & ST-45 & Chicken & \\
\hline Chick2213 & C. jejuni & ST-45 & Chicken & \\
\hline Cow518 & C. jejuni & ST-21 & Cattle & High \\
\hline CampsClin53 & C. jejuni & ST-21 & Human & \\
\hline Cow58 & C. jejuni & - & Cattle & \\
\hline Cowa21 & C. jejuni & ST-21 & Cattle & \\
\hline Chickc21 & C. jejuni & ST-21 & Chicken & \\
\hline Chick25 & C. jejuni & ST-661 & Chicken & \\
\hline Chick104 & C. jejuni & ST-21 & Chicken & \\
\hline Chick353 & C. jejuni & ST-353 & Chicken & \\
\hline Chickb354 & C. jejuni & ST-354 & Chicken & \\
\hline Chick573 & C. jejuni & ST-573 & Chicken & \\
\hline Chick2568 & C. jejuni & ST-661 & Chicken & \\
\hline Chickc45 & C. jejuni & ST-45 & Chicken & Low \\
\hline Chick19 & C. jejuni & ST-21 & Chicken & Low \\
\hline Chick50 & C. jejuni & ST-21 & Chicken & High \\
\hline Chick53 & C. jejuni & ST-21 & Chicken & Low \\
\hline Chick262 & C. jejuni & ST-21 & Chicken & \\
\hline Chick266 & C. jejuni & ST-21 & Chicken & \\
\hline Chick861 & C. jejuni & - & Chicken & \\
\hline Chick1086 & C. jejuni & ST-21 & Chicken & \\
\hline Chick1360 & C. jejuni & ST-21 & Chicken & \\
\hline Chick11 & C. jejuni & ST-45 & Chicken & \\
\hline Chick137 & C. jejuni & ST-257 & Chicken & High \\
\hline Chick1003 & C. jejuni & ST-45 & Chicken & \\
\hline Chick2048 & C. jejuni & ST-45 & Chicken & \\
\hline Chick2197 & C. jejuni & ST-354 & Chicken & \\
\hline Chick2223 & C. jejuni & ST-45 & Chicken & Low \\
\hline Cow3583 & C. jejuni & ST-42 & Cattle & Low \\
\hline
\end{tabular}

(Continued)
TABLE 2 | Continued

\begin{tabular}{|c|c|c|c|c|}
\hline Isolate & Species & Clonal complex & Source & IL-8 \\
\hline Cow618 & C. jejuni & ST-61 & Cattle & Low \\
\hline Cow237 & C. jejuni & ST-206 & Cattle & High \\
\hline Cow270 & C. jejuni & ST-403 & Cattle & Low \\
\hline Cowb21 & C. jejuni & ST-21 & Cattle & \\
\hline Cowb45 & C. jejuni & ST-45 & Cattle & \\
\hline Cowc45 & C. jejuni & ST-45 & Cattle & \\
\hline Cowd45 & C. jejuni & ST-45 & Cattle & \\
\hline Cow53 & C. jejuni & ST-21 & Cattle & \\
\hline Cow104 & C. jejuni & ST-21 & Cattle & Low \\
\hline Cow3189 & C. jejuni & - & Cattle & High \\
\hline Cow3201 & C. jejuni & ST-21 & Cattle & \\
\hline Cow3205 & C. jejuni & ST-206 & Cattle & \\
\hline Cow137 & C. jejuni & ST-45 & Cattle & \\
\hline Cow230 & C. jejuni & - & Cattle & \\
\hline Cow583 & C. jejuni & ST-45 & Cattle & \\
\hline Cow3207 & C. jejuni & ST-45 & Cattle & High \\
\hline Cow3214 & C. jejuni & ST-45 & Cattle & \\
\hline Chick354 & C. jejuni & ST-257 & Chicken & \\
\hline Chick51 & C. jejuni & ST-443 & Chicken & \\
\hline Chick1079 & C. jejuni & ST-573 & Chicken & Low \\
\hline Chick574 & C. jejuni & ST-574 & Chicken & \\
\hline Chick814 & C. jejuni & ST-661 & Chicken & \\
\hline Chickb21 & C. jejuni & ST-21 & Chicken & \\
\hline Chickb45 & C. jejuni & ST-45 & Chicken & \\
\hline Chickd45 & C. jejuni & ST-45 & Chicken & High \\
\hline Chick883 & C. jejuni & ST-21 & Chicken & \\
\hline Chick230 & C. jejuni & ST-45 & Chicken & \\
\hline Chick2663 & C. jejuni & ST-45 & Chicken & \\
\hline CampsClin21 & C. jejuni & - & Human & High \\
\hline OxClina21 & C. jejuni & ST-21 & Human & \\
\hline OxClinb21 & C. jejuni & ST-45 & Human & Low \\
\hline OxClina45 & C. jejuni & ST-45 & Human & High \\
\hline OxClinb45 & C. jejuni & ST-21 & Human & High \\
\hline Starling177 & C. jejuni & ST-177 & Starling & Low \\
\hline Starling682 & C. jejuni & ST-682 & Starling & Low \\
\hline Starling 45 & C. jejuni & ST-45 & Starling & \\
\hline Starling1020 & C. jejuni & ST-682 & Starling & Low \\
\hline Goose1033 & C. jejuni & ST-1034 & Goose & High \\
\hline Goose702 & C. jejuni & - & Goose & Low \\
\hline Goose137 & C. jejuni & ST-45 & Goose & Low \\
\hline Goose696 & C. jejuni & ST-1332 & Goose & Low \\
\hline Duck702 & C. jejuni & ST-702 & Duck & \\
\hline Duck45 & C. jejuni & ST-45 & Duck & Low \\
\hline CAMP2381 & C. jejuni & - & Environmental waters & \\
\hline NCTC11168 & C. jejuni & ST-21 & Human & High \\
\hline M1 & C. jejuni & ST-45 & Human & High \\
\hline
\end{tabular}

\section{C. jejuni-Induced Cytokine Production Infection of Epithelial Cell Monolayers}

Cell monolayers, containing $3.5 \times 10^{5}$ cells/well, grown in a 24-well tissue culture plate were infected with $5 \times 10^{6} \mathrm{cfu}$ of C. jejuni for $24 \mathrm{~h}$ at $37^{\circ} \mathrm{C}$ in a $5 \% \mathrm{CO}_{2}$ atmosphere to allow the bacteria to adhere to and invade the host cells. 
TABLE 3 | Primer sequences used in this study.

\begin{tabular}{|c|c|c|c|c|c|c|}
\hline Genbank & cDNA & bp & AA & Primer sequence & Annealing $\mathrm{T}^{\circ} \mathrm{C}$ & Expected size (Kb) \\
\hline BC013615.1 & Human IL-8 & 300 & 99 & $\begin{array}{l}\text { cagttttgccaaggagtgct } \\
\text { ttggggtggaaaggtttgga }\end{array}$ & 60 & 73 \\
\hline NM_205018.1 & Chicken CXCLi1 & 315 & 104 & $\begin{array}{l}\text { cgattgaactccgatgccag } \\
\text { cattcttgcagtgaggtccg }\end{array}$ & 59 & 105 \\
\hline NM_205498.1 & Chicken CXCLi2 & 312 & 103 & $\begin{array}{l}\text { ggatggaagagaggtgtgct } \\
\text { ctgagccttggccataagtg }\end{array}$ & 59 & 79 \\
\hline NM_000572 & Human IL-10 & 537 & 178 & $\begin{array}{l}\text { ggcgctgtcatcgatttctt } \\
\text { cattcttcacctgctccacg }\end{array}$ & 60 & 63 \\
\hline AJ621254.1 & Chicken IL-10 & 528 & 175 & $\begin{array}{l}\text { acatccaactgctcagctct } \\
\text { atgctctgctgatgactggt }\end{array}$ & 59 & 142 \\
\hline X00351.1 & Human $\beta$-actin & 1128 & 375 & $\begin{array}{l}\text { tggcatccacgaaactacct } \\
\text { cgtacaggtctttgcggatg }\end{array}$ & 60 & 68 \\
\hline L08165.1 & Chicken $\beta$-actin & 1128 & 375 & $\begin{array}{l}\text { aagatcattgccccacctga } \\
\text { cctgcttgctgatccacatc }\end{array}$ & 59 & 100 \\
\hline
\end{tabular}

\section{RNA Isolation from Infected Epithelial Cells}

Following the infection period, total RNA was isolated from HT-29 human or 8E11 chicken intestinal epithelial cells grown in a 24 well plate using the method provided with the Promega SV total RNA isolation kit (Promega, Southampton, United Kingdom). Total RNA was quantified using a NanoDrop (Thermo scientific, Loughborough, United Kingdom) and run through a $0.7 \%$ agarose gel using a $1 \mathrm{~kb}$ and $100 \mathrm{bp}$ ladders to confirm integrity.

\section{Quantitative PCR of Cytokine RNA Transcripts from Infected Monolayers}

One microgram of total RNA was converted to cDNA using an iScript kit (Bio-Rad). Quantitative PCR was used to amplify the gene of interest and the housekeeping gene. Each reaction $(25 \mu \mathrm{l})$ contained $12.5 \mu \mathrm{l} 2 \mathrm{X}$ Sensimix SYBR buffer (Bioline), $0.5 \mu \mathrm{l}$ each primer $(25 \mu \mathrm{M}), 9.5 \mu \mathrm{l}$ purified water and $2 \mu \mathrm{lcDNA}$. The qPCR conditions were as follows; $10 \mathrm{~min}$ at $95^{\circ} \mathrm{C}$, then 50 cycles with denaturing for $15 \mathrm{~s}$ at $95^{\circ} \mathrm{C}$, annealing for $15 \mathrm{~s}$ at temperatures specific to primers sets (Table 3 ) and synthesis at $72^{\circ} \mathrm{C}$. Reactions were performed in an iCycler (Bio-Rad). Primer efficiency was measured using total RNA from epithelial cells infected with a reference C. jejuni isolate (NCTC11168) and a dilution series up to $1 / 10,000$. The log values of the Cycle threshold (CT) values were then taken and plotted graphically and the slopes used to calculate the efficiency. Relative transcriptional levels within distinct experiments were determined by using the $2^{-\Delta \Delta} \mathrm{Ct}$ method and $\beta$-actin as the reference housekeeping gene (Livak and Schmittgen, 2001). Primer sequences for human IL8 , IL-10, and $\beta$-actin and chicken CXCLi1/2 and $\beta$-actin were used to create primers for qPCR (Table 3). Target sequences were identified from the NCBI database and then the coding sequence (CDS) was used to generate forward and reverse primers using Primer3, selecting for amplicon sizes of 50-150 bases.

\section{Invasion and Adhesion}

Bacterial strains were inoculated onto plates and grown in a microaerobic environment for $48 \mathrm{~h}$. A colony of freshly grown culture was sub-cultured in $\mathrm{MH}$ broth for $24 \mathrm{~h}$, as described previously. Then, $5 \times 10^{6} \mathrm{cfu}$ of bacterial suspension was added to the wells containing monolayers of cells in assay medium (modified McCoy's 5A/DMEM/F-12 with L-glutamine (5 mM) and supplemented with 5\% FBS) for $6 \mathrm{~h}$. The rest of the broth was serially diluted in PBS and plated out onto Columbia blood agar (COLBA) plates for enumeration of C. jejuni. Monolayers of cells were grown in a 6-well tissue culture plate as previously discussed. For the adhesion assay, the monolayer cells incubated with bacteria were washed three times with PBS and then incubated with maximum recovery diluent for $10 \mathrm{~min}$ (1.5 $\mathrm{g}$ peptone, $8.5 \mathrm{~g}$ sodium chloride, per liter; final $\mathrm{pH}$ 7.0) to remove unbound bacteria. Plates were shaken and adhering C. jejuni cells were removed and serially diluted in maximum recovery diluent and plated out onto COLBA for enumeration. For the invasion assay, the monolayer cells incubated with bacteria were washed twice with PBS before $2 \mathrm{ml}$ gentamicin in PBS $(100 \mu \mathrm{g} / \mathrm{ml})$ was added to each well and incubated at $37^{\circ} \mathrm{C}$ for $90 \mathrm{~min}$. Timecourse analysis confirmed that Campylobacter strains were killed between 60 and 90 min after gentamicin exposure with longer times affecting intracellular Campylobacter counts. Cells were washed twice with PBS before $2 \mathrm{ml} 0.1 \%$ Triton X-100 in PBS was added to each well in order to lyse the cells. After 5 min, cell lysates were serially diluted in PBS and plated out on COLBA plates for enumeration of the invasive bacteria. This experiment was performed four times. The limit of detection was $50 \mathrm{CFU} / \mathrm{ml}$.

\section{Inhibition Assays}

A series of known endocytosis and signaling inhibitors were used to block cellular processes (Table 4). Cells were cultured as described above for infection experiments, except that HT-29 and $8 \mathrm{E} 11$ cells were treated with each inhibitor separately for $30 \mathrm{~min}$ and prior to infection with Campylobacter and subsequent invasion assays and RNA isolation/qPCR. Initial inhibitor concentration ranges were identified from their previous use in HT-29 epithelial cells and/or Campylobacter invasion studies (Wooldridge et al., 1996; Wells et al., 
TABLE 4 | List of Inhibitors used in study.

\begin{tabular}{|c|c|c|}
\hline Inhibitor & Pathway/mechanism & Reference \\
\hline 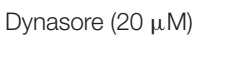 & $\begin{array}{l}\text { Dynamin - Endocytosis, } \\
\text { Dynamin GTPase activity }\end{array}$ & $\begin{array}{l}\text { Macia et al., } \\
2006\end{array}$ \\
\hline Filipin $(20 \mu \mathrm{M})$ & $\begin{array}{l}\text { Lipid raft Caveolin pathway } \\
\text { Endocytosis }\end{array}$ & $\begin{array}{l}\text { Bonneau et al., } \\
2010\end{array}$ \\
\hline Genistein (20 $\mu \mathrm{M})$ & $\begin{array}{l}\text { Caveolin Endocytosis, tyrosine } \\
\text { kinase inhibitor }\end{array}$ & $\begin{array}{l}\text { Akiyama et al., } \\
1987\end{array}$ \\
\hline $\begin{array}{l}\text { Chlorpromazine } \\
(20 \mathrm{mM})\end{array}$ & $\begin{array}{l}\text { Clathrin Endocytosis, clathrin } \\
\text { misassembly }\end{array}$ & Lee et al., 2007 \\
\hline LY294002 (20 нM) & Pl-3 Kinase & $\begin{array}{l}\text { Chaussade } \\
\text { et al., } 2007\end{array}$ \\
\hline $\begin{array}{l}\text { InSolution }{ }^{\mathrm{TM}} \text { Akt } \\
\text { Inhibitor } \mathrm{V} \text {, Triciribine } \\
(20 \mu \mathrm{M})\end{array}$ & Akt & $\begin{array}{l}\text { Karst et al., } \\
2006\end{array}$ \\
\hline PD98059 (20 нM) & ERK/MEK & $\begin{array}{l}\text { Alessi et al., } \\
1995\end{array}$ \\
\hline Cytochalasin D & Actin polymerization & $\begin{array}{l}\text { Goddette and } \\
\text { Frieden, } 1986\end{array}$ \\
\hline Methyl $\beta$-cytodextrin & $\begin{array}{l}\text { Lipid rafts/extraction of } \\
\text { cholesterol }\end{array}$ & $\begin{array}{l}\text { Rodal et al., } \\
1999\end{array}$ \\
\hline
\end{tabular}

1998, 1999; Hickey et al., 2000; Jin et al., 2003; Fernandez de Mattos et al., 2008; Weflen et al., 2010; Colin et al., 2011; Li et al., 2011). The optimal concentrations (Table 4) which include, Dynasore $(20 \mu \mathrm{M})$, filipin, $(20 \mu \mathrm{M})$, genistein (20 $\mu \mathrm{M})$, chlorpromazine $(20 \mu \mathrm{M})$, LY294002 $(20 \mu \mathrm{M})$, In solution Akt inhibitor $\mathrm{V}$, Triciribine $(20 \mu \mathrm{M})$, PD98059 $(20 \mu \mathrm{M})$, methyl $\beta$-cytodextrin $(5 \mu \mathrm{M})$ and cytochalasin $\mathrm{D}$ $(5 \mu \mathrm{M})$ are the highest concentrations used in this study that did not result in significant decreases in toxicity using the alamar blue assay on both HT-29 and 8E11 epithelial cells.

\section{Statistical Analysis}

The non-parametric Kruskal-Wallis test, for multiple comparisons with post hoc Dunns test was used. Correlations were assessed using linear regression of log transformed data with a $p$-value related to the slope. Significance differences were accepted if $p \leq 0.05$. Graphpad Prism 6.0 (San Diego, CA, United States) was used to analyze and assess differences between treatment groups.

\section{RESULTS}

\section{C. jejuni Strains in the Study Population}

To investigate the diversity of human and avian epithelial cell innate immune responses, 100 strains of $C$. jejuni were selected from across a phylogenetic tree (Figure 1 and Table 2). This included isolates from a variety of sequence types, and the major clonal complexes CC-45 and CC21 (Figure 1). In addition, strains were selected based on the source of the isolate and included, human, chicken, cattle, and wild-bird isolates (Figure 1).

\section{C. jejuni Strains Produce a Large Variation in Inflammatory Cytokine Responses}

Inflammatory phenotype was investigated by infecting human and avian epithelial cells with the $C$. jejuni strain collection $(n=100)$. IL- 8 or CXCLi1 and CXCLi2 expression in these cells showed dramatic changes compared to uninfected ones with up to 100,000-fold increases in both human and avian cells (Figure 2A). Despite the large variation, human IL-8 and avian CXCLi2 expression were significantly increased compared to CXCLi1 ( $p \leq 0.01$ and $p \leq 0.01$, respectively). There was no difference between IL- 8 and CXCLi2 expression. The reference strains NCTC11168 and M1 produced IL-8 and CXCLi1 responses similar to the average for the whole C. jejuni study population. The average C. jejuni induced CXCLi2 response was similar to that of the M1 but the 11168 strain-induced response was 11-fold higher. We could not identify differences in responses between sources and sequence types.

The anti-inflammatory cytokine IL-10 also displayed infection-induced increase in expression and variability compared to uninfected control $(p \leq 0.001)$ in both HT-29 and $8 \mathrm{E} 11$ cells. In addition, IL-10 expression was significantly increased $(p<0.01)$ in 8E11 cells compared to that in HT-29 ones (Figure 2B). The reference strains NCTC11168 and M1 produced IL-10 responses similar to the average for the whole C. jejuni study population. As above, we could not identify any difference in responses between sources and sequence types.

We then chose eight strains of $C$. jejuni that produced the strongest cytokine responses and investigated whether they affect common signaling pathways (PI 3-kinase/Akt and ERK) differently in human and avian epithelial cells (Figures 2C-E). Inhibition of signaling pathways showed that IL-8 expression in HT-29 cells and CXCLi1 and CXCLi2 in 8E11 cells were all ERK-dependent ( $p<0.001, p<0.01$, and $p<0.05$, respectively). Furthermore, PI 3-kinase and Akt pathways did not appear to be required for IL- 8 or CXCLi1/2 production. In contrast, IL-10 expression in human and avian cells was dependent on PI 3 -Kinase and its downstream target Akt but was independent of ERK (Figures 2F,G).

These results confirm that similar signaling pathways are responsible for IL-8 and IL-10 expression in human and avian epithelial cells.

\section{C. jejuni Invasion Is ERK-Dependent in Human and Avian Epithelial Cells}

We investigated the ability of high and low IL-8 (or CXCLi1/2)inducing $C$. jejuni strains ( $n=35$, final column Table 2 ) to adhere to and invade human and avian epithelial cells. No significant difference was detected in adherence to human and avian epithelial cells (Figure 3A) although adhesion levels to avian cells had a wider distribution. Gentamicin protection assays in both cell lines showed that all strains tested were able to invade intestinal epithelial cells in both human and avian systems (Figure 3B), which ranged from 1 to $3 \%$ of the starting inoculum. While each strain produced a unique invasion 
A

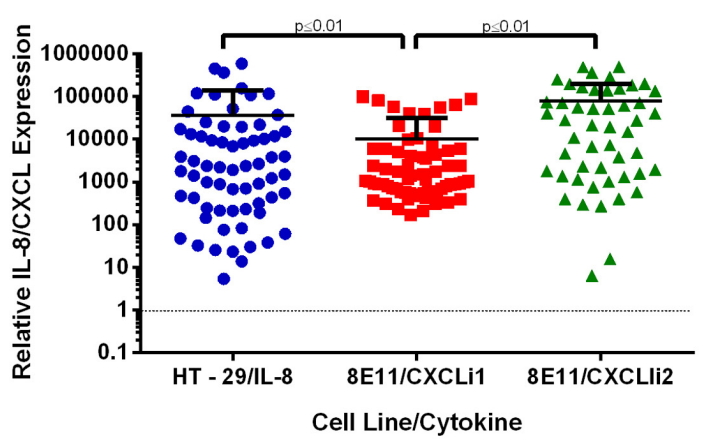

C

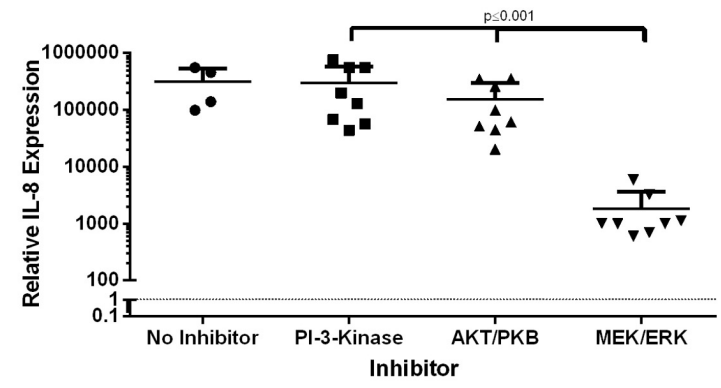

E

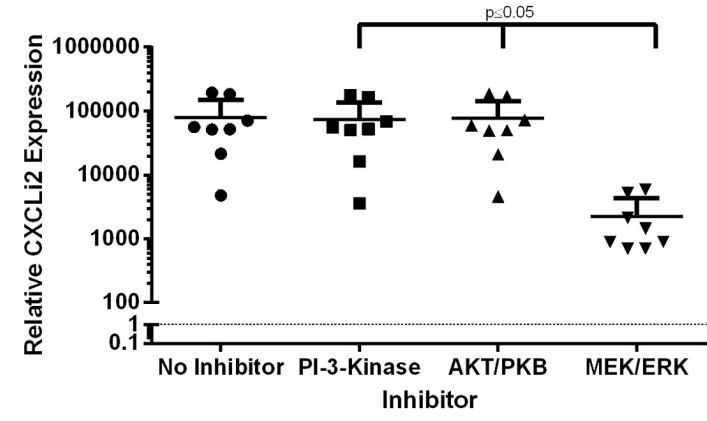

B

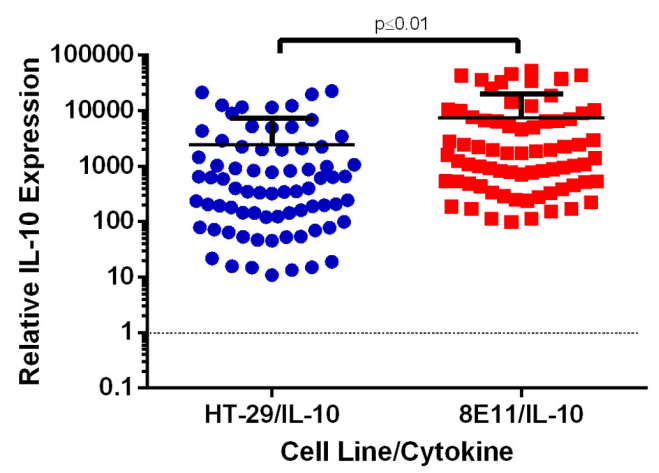

D

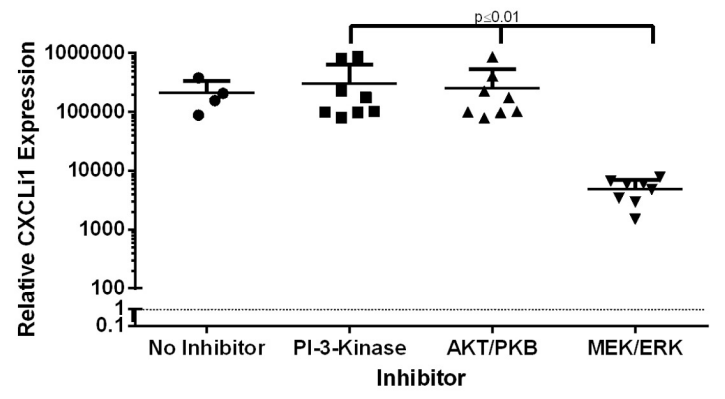

$\mathbf{F}$

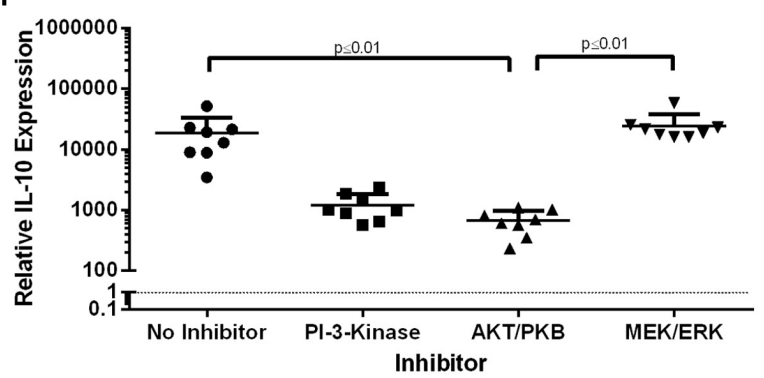

G

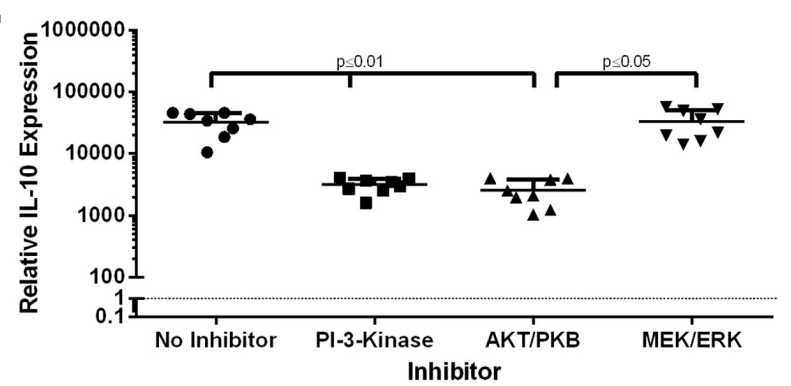

FIGURE 2 | Expression of pro- and anti- inflammatory cytokines and chemokine's in HT-29 human and 8E11 chicken epithelial cells. HT-29 and 8E11 cells were infected with C. jejuni for $24 \mathrm{~h}$ before isolation of total RNA and quantification of specific mRNA by qPCR. (A) Expression of IL-8/CXCLi1/CXCLi2 in both HT-29 and 8E11 cell lines (B) expression of IL-10 in HT-29 and 8E11 cell lines. (C-G) Prior to infection, cells were incubated with signaling inhibitors for up to 30 min. Then specific mRNA for IL-8/CXCLi1/CXCLi2 (C-E) and IL-10 (F,G) were measured. Each dot represents three biological replicates in one strain. Results are also expressed as mean $\pm \mathrm{SD}$ of all strains measured. Differences were considered significant if $p \leq 0.05$.

response no significant difference in the invasion was observed between human and avian cells. Inhibition of epithelial cell signaling pathways with 'high' invasive strains $(n=8)$ confirmed the role of ERK in C. jejuni invasion of human (Figure 3C) and avian (Figure 3D) epithelial cells $(p \leq 0.001$ in both cases). 
A

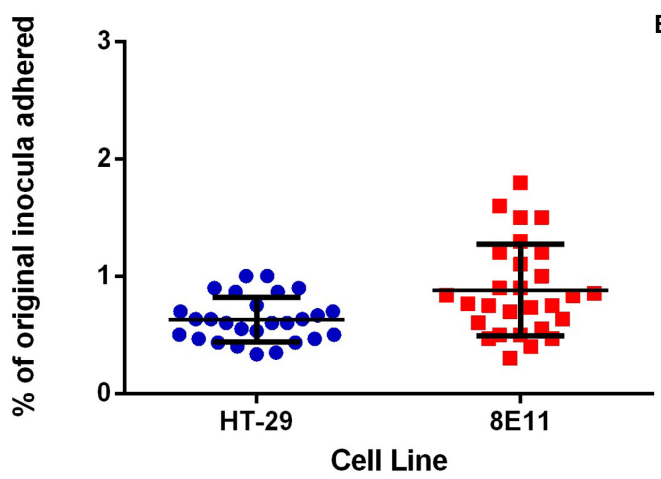

C

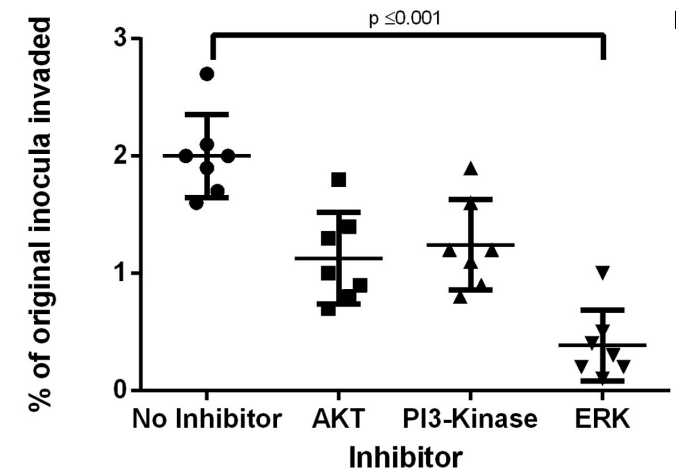

B

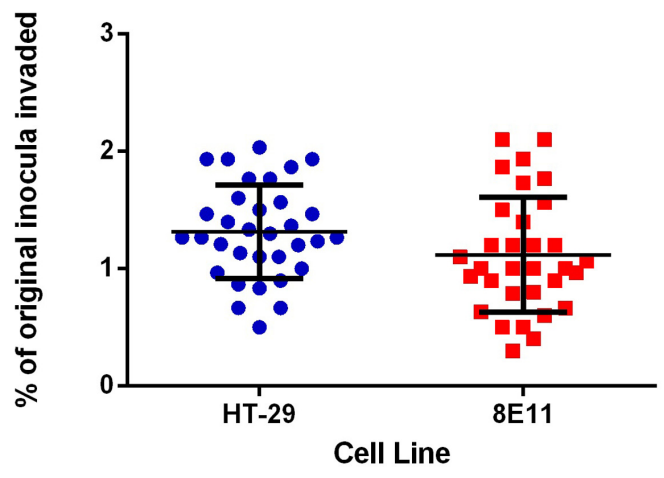

D

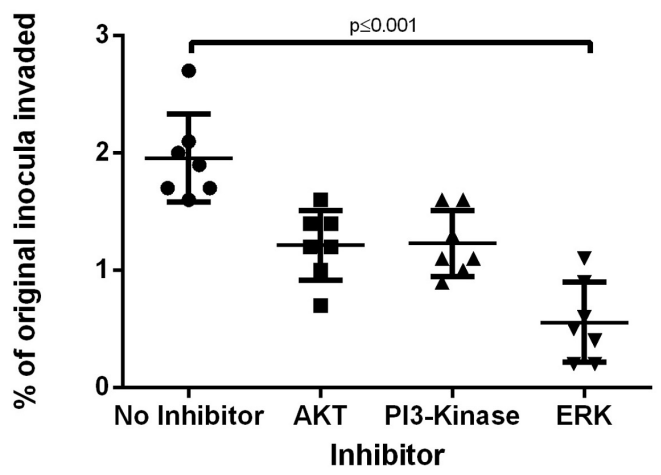

FIGURE 3 | Adhesion and Invasion of C. jejuni into HT-29 and 8E11 cells. HT-29 and 8E11 cells were infected with C. jejuni for $6 \mathrm{~h}$ before isolation and quantification of adherent and invasive C. jejuni. (A) Adhesion of C. jejuni strains to HT-29 and 8E11 cells. (B) Invasion of C. jejuni into HT-29 and 8E11 cells. (C,D) Treatment of HT-29 and $8 \mathrm{E} 11$ cells with signaling inhibitors for 30 min prior to invasion assays. Each dot represents three biological replicates in one strain. Results are also expressed as mean $\pm \mathrm{SD}$ of all strains measured. Differences were considered significant if $p \leq 0.05$.

These results confirm the different invasion responses of individual C. jejuni strains despite all requiring ERK for a full invasion response.

\section{The cdtA Gene Has an Important Role in C. jejuni-Induced Epithelial Cell Toxicity}

Campylobacter invasion can compromise epithelial cell viability and we investigated toxicity responses of all C. jejuni strains (Figure 4, $n=100$ ). The toxicity of $C$. jejuni for both human and avian cells showed unique profiles for each strain tested. Epithelial cells infected with any $C$. jejuni strain showed increased toxicity compared to untreated cells but only a few C. jejuni strains induced high toxicity responses (over $50 \%$ reduction in viability, Figure 4A). We could not identify differences between sources and sequence types. $c d t A$-positive strains were significantly more toxic than -negative ones, in both human (Figure 4B, $p \leq 0.0001$ ) and avian epithelial cells (Figure 4C, $p \leq 0.001$ ).

\section{C. jejuni-Induced IL-8 Production, Toxicity and Invasion of Epithelial Cells Are More Closely Correlated in Avian Cells Than in Human Ones}

Given that both IL-8/CXCLi1/CXCLi2 production and invasion were ERK-dependent across the collection of $C$. jejuni strains, we investigated whether correlations existed between the measured phenotypes of IL-8/CXCLi1/CXCLi2 production, invasion and toxicity. IL-8 (Figure 5A, $p<0.4$ ) or CXCLi2 (Figure 5C, $p<0.3$ ) expression did not correlate with Campylobacter invasion whereas CXCLil (Figure 5B, $p<0.023$ ) expression showed strong positive correlations with invasion. IL-8 $(p<0.007)$, CXCLi1 $(p<0.0082)$, and CXCLi2 $(p<0.0339)$ all positively correlated with cell toxicity (Figures 5D-F). Finally, invasion and toxicity were strongly correlated in both human $(p<0.0078)$ and avian $(p<0.0078)$ cells (Figures 5G,H).

These correlations confirm a close interrelationship between (i) C. jejuni-induced cytokine expression and toxicity and (ii) between toxicity and cellular invasion.

\section{Endocytosis of C. jejuni Is Dynamin- and Clathrin-Dependent in Both Human and Avian Epithelial Cells}

Having confirmed the importance of ERK in downstream signaling for invasion, we next investigated upstream pathways at the cell surface important for endocytosis. Both Methyl$\beta$-cyclodextrin and cytochalasin D completely abrogated C. jejuni $(n=31)$ invasion into both cell lines (Supplementary Figure S1) confirming the role of lipid rafts and the actin cytoskeleton, respectively. Pre-treatment of epithelial cells with a dynamin 
A

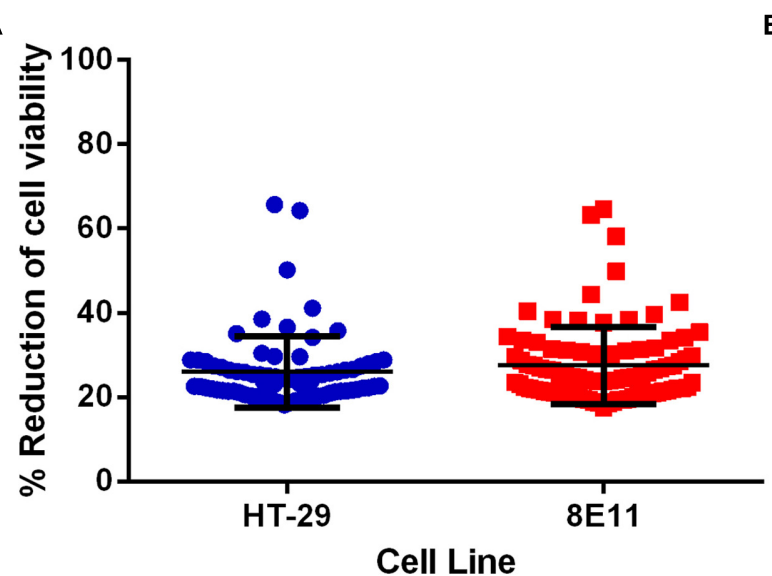

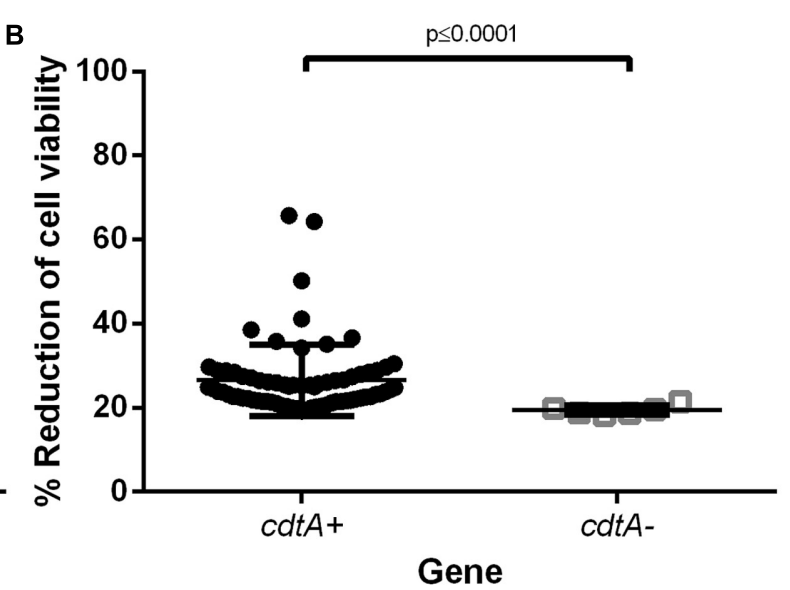

C

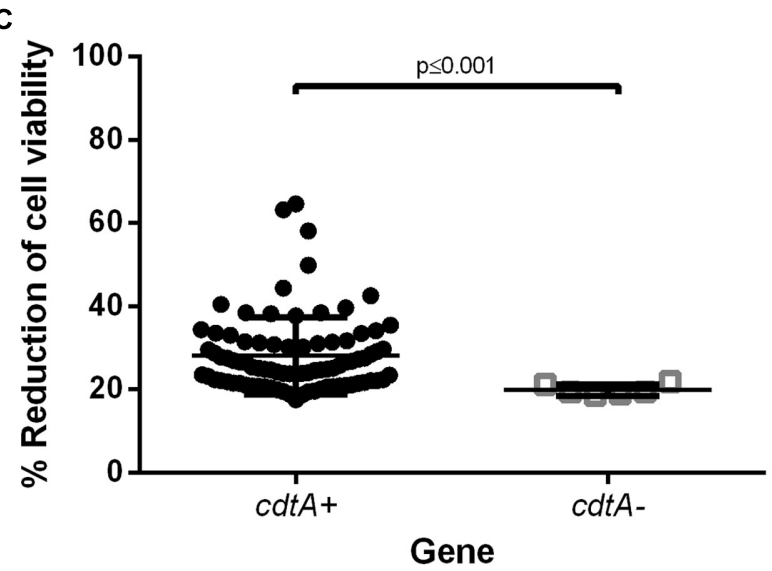

FIGURE 4 | Reduction of cell viability after infection with C. jejuni. HT-29 and 8E11 cells were infected with C. jejuni for $24 \mathrm{~h}$ before isolation of cell supernatants for alamar blue viability assay. (A) Toxicity responses in HT-29 and 8E11 epithelial cells. (B,C) Toxicity responses organized by the presence and absence of the cdtA gene. Each dot represents three biological replicates in one strain. Results are also expressed as mean \pm SD of all strains measured. Differences were considered significant if $p \leq 0.05$.

inhibitor (Dynasore) and a clathrin inhibitor (chlorpromazine) significantly reduced C. jejuni invasion in human (Figure 6A) and avian (Figure 6B) cells compared to the 'no' inhibitor control. This is confirmed by concomitant reduction in cellular toxicity in the relevant cultures (data not shown). In addition, caveolin-dependent endocytosis was tested using filipin and genistein with no consistent effect observed over triplicate experiments. These results confirm the importance of clathrin and dynamin in C. jejuni invasion.

\section{C. jejuni-Induced IL-8 and CXCLi1/2 Expression Is Dynamin- and Clathrin-Dependent in Human and Avian Epithelial Cells}

Cytokine expression was also determined following manipulation of endocytosis pathways. Consistent with invasion responses (Figure 6), IL-8 expression (Figure 7A) in human cells and CXCLi1 (Figure 7B) and CXCLi2 (Figure 7C) expression in avian cells was dependent on dynamin and clathrin (Figure 7). In contrast to invasion responses, inhibition of caveolin pathways also significantly reduced IL-8, CXCLi1 and 2 expression (data not shown). Cytokine expression could be detected in the absence of toxicity and with minimal invasion responses (Figures 6, 7). These results confirm the importance of clathrin, caveolin and dynamin for C. jejuni-induced IL-8 production.

\section{DISCUSSION}

The data in this paper add to the growing body of evidence that supports the idea that C. jejuni is a pathogen in chickens (Neill et al., 1984; Byrne et al., 2007; Jennings et al., 2011; Williams et al., 2013; Humphrey et al., 2014). Thus, C. jejuni induce inflammatory and toxicity responses and can also invade human and importantly avian epithelial cell lines. While there was little difference between human and avian cell responses, there was a wide range across all bacterial strains studied. We deliberately chose 100 strains of $C$. jejuni from a variety of sources (including chicken, human, cattle, and wild birds) and across sequence types 
$\mathbf{A}$

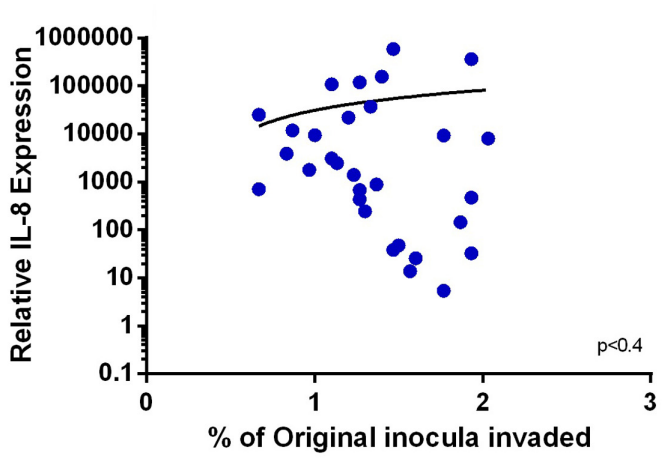

C

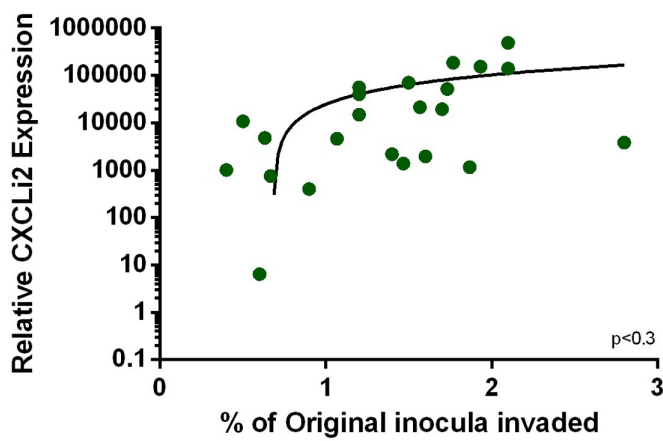

E

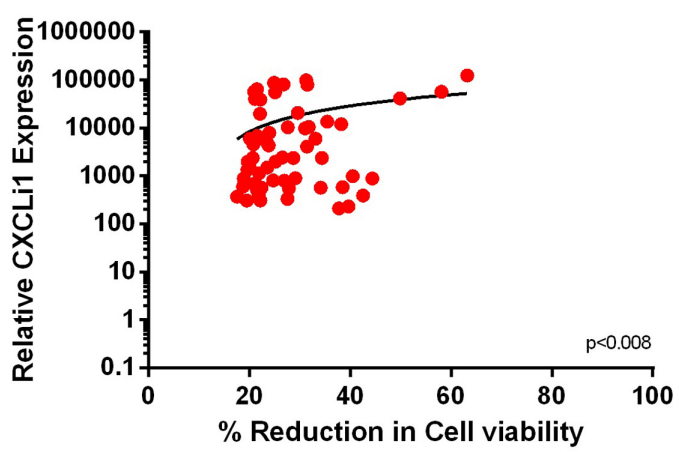

G

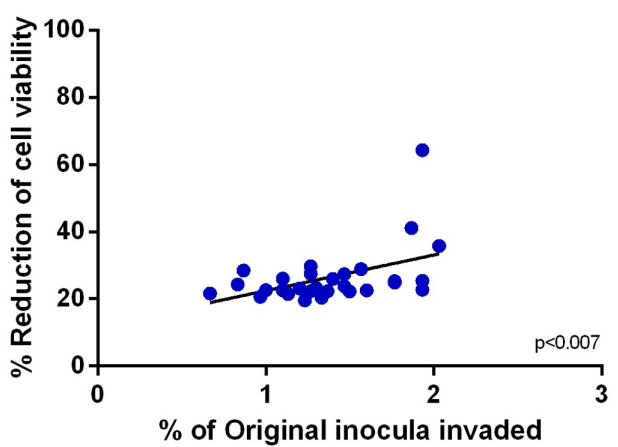

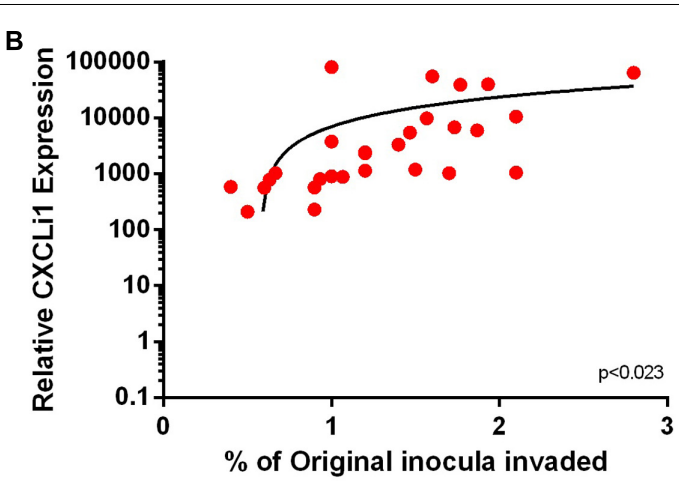

D

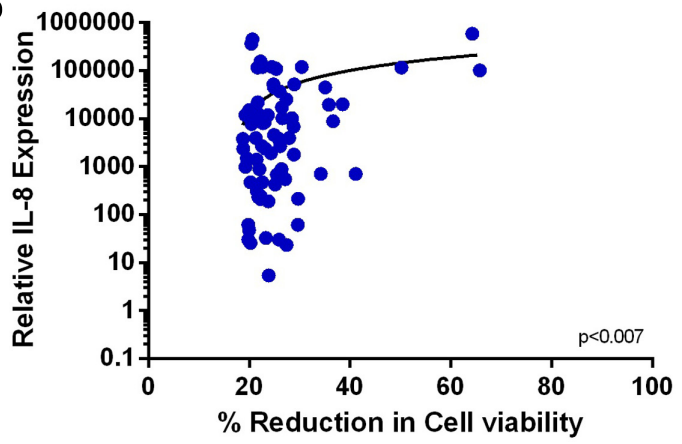

F

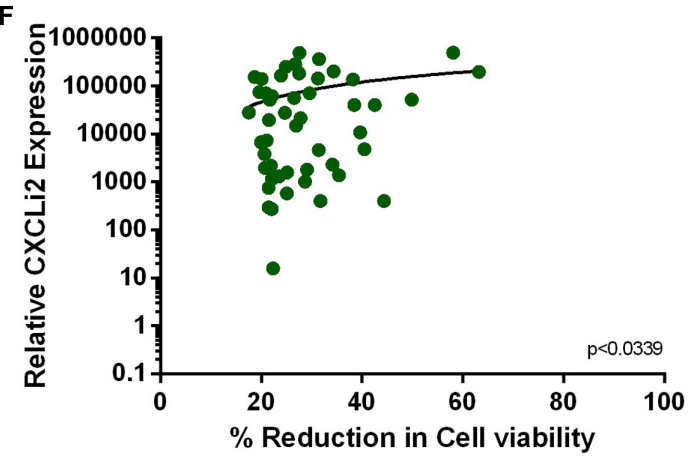

H

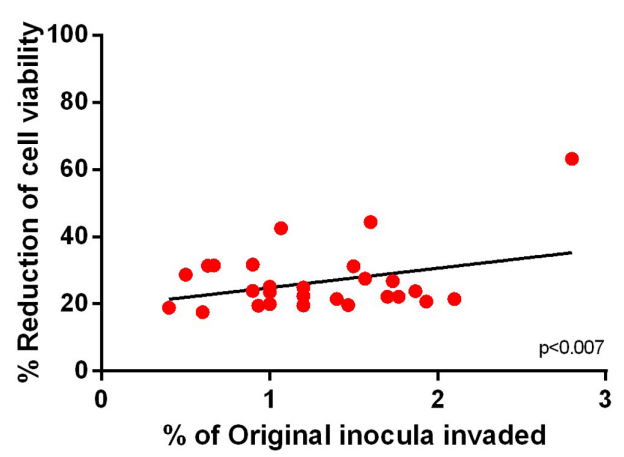

FIGURE 5 | Relationships between C. jejuni-induced cellular invasion, toxicity and cytokine production. Phenotypic data was subjected to regression analysis. (A) IL-8 (B) CXCLi1 and (C) CXCLi2 correlations with C. jejuni invasion. (D) IL-8, (E) CXCLi1, (F) CXCLi2 correlations with toxicity. (G) HT29 cell viability correlation with invasion $\mathbf{( H )} 8 \mathrm{E} 11$ cell viability correlation with invasion. 


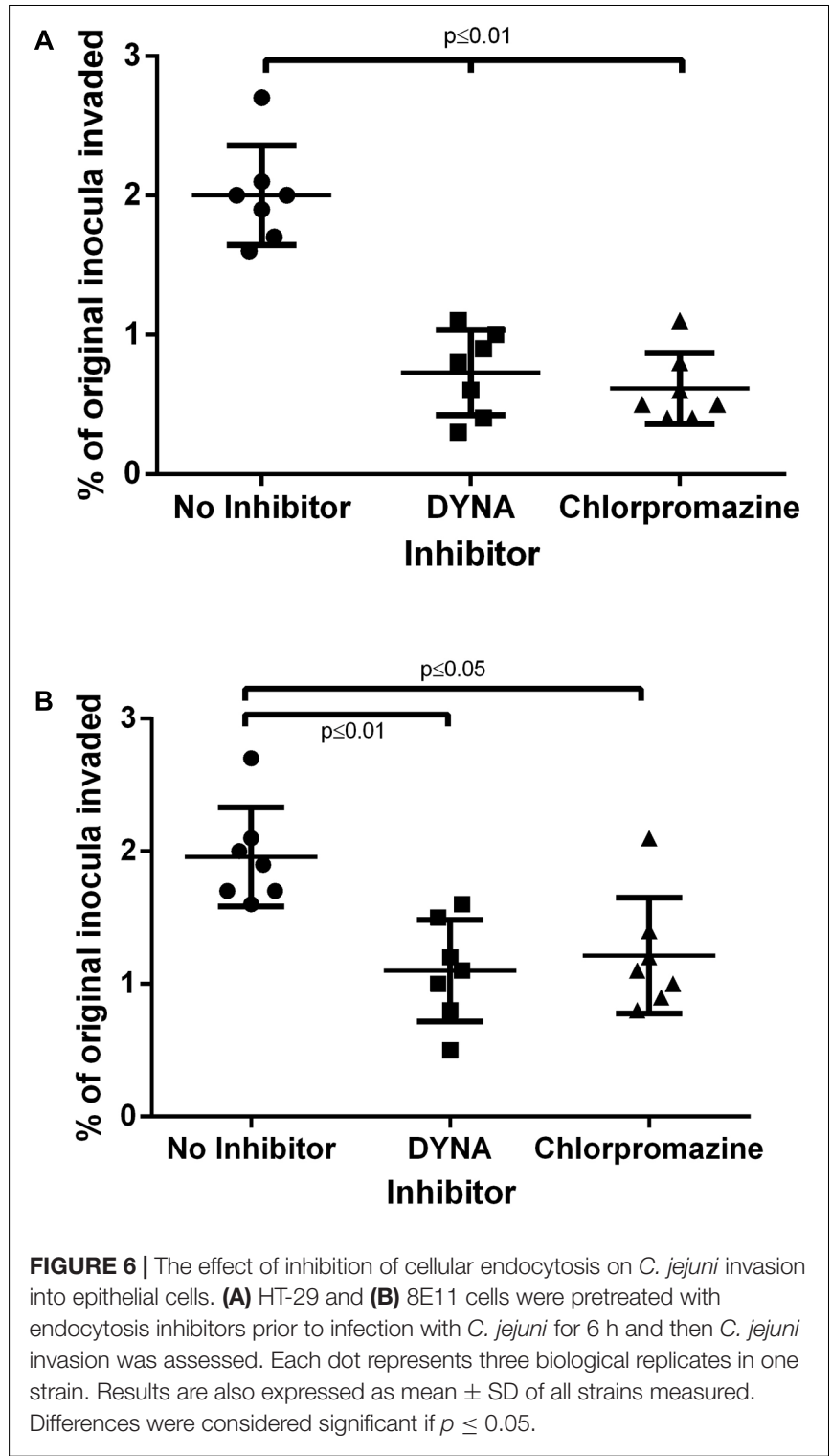

to give a good representation of strains studied previously at the genomic level although we did not detect differences between these groups (Sheppard et al., 2011, 2013). Coincidentally, the reference strains M1 and NCTC11168 produced responses equivalent to the average for the whole study population. The question remains as to the source of the variation across the whole population. Interestingly, the presence of key virulence factors associated with $C$. jejuni pathogenesis was relatively high $(>80 \%$, Table 1) and thus differential gene expression may be responsible for the dramatic differences in epithelial cell responses. We did not measure individual virulence factor expression in this study but previous work on the transcriptome of a variety of Campylobacter strains showed that they are subject to complex regulation (Dugar et al., 2013).

Epithelial-derived IL-8 production is vital for early neutrophil infiltration into the gut in humans (Bennett et al., 2010) and chickens (Humphrey et al., 2014). This study confirms

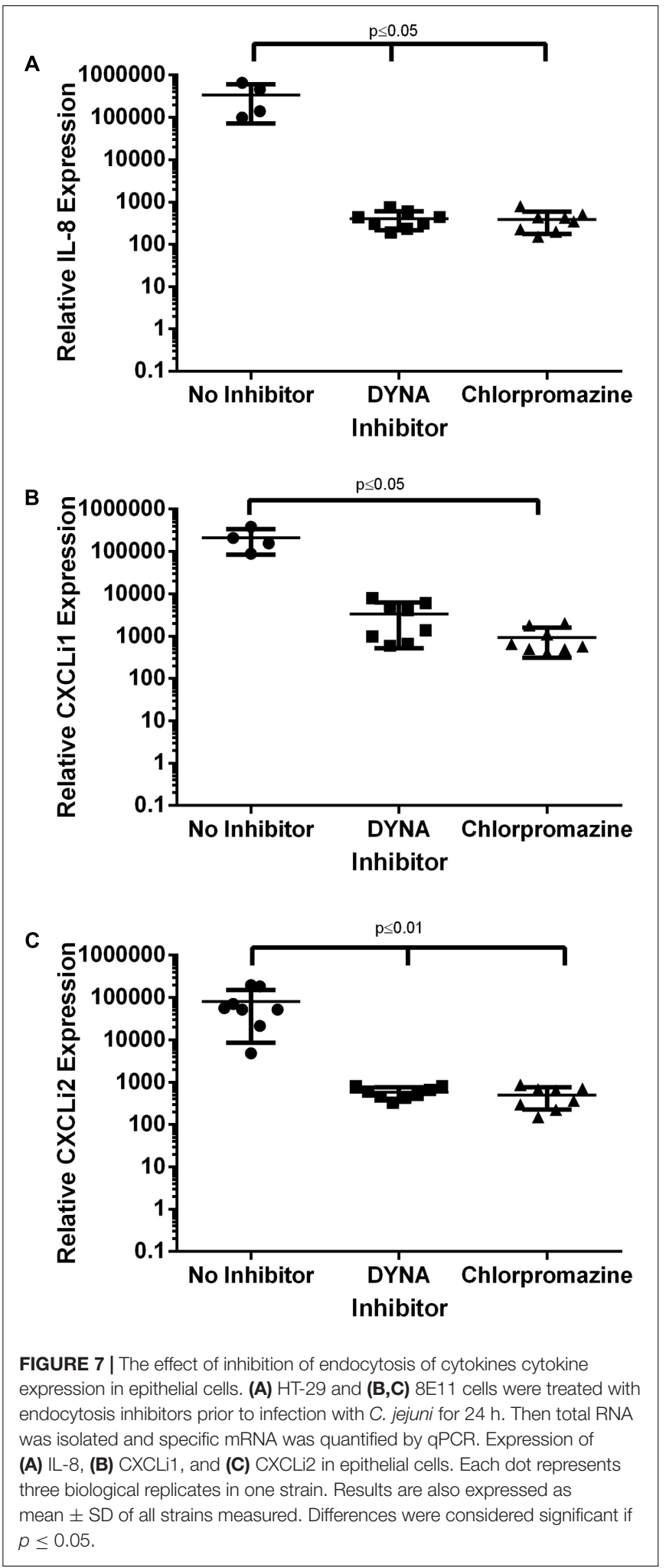

the importance of human IL-8 and identifies both CXCLi1 and CXCLi2 as important early chemokines induced in avian epithelial cells following C. jejuni infection. This is consistent with studies in chicken LMH epithelial cells (Larson et al., 2008). 
Interestingly, CXCLi2 (like human IL-8) was significantly higher than CXCLi1. To our knowledge this is the first time that a study using a large collection of $C$. jejuni strains has found differences in these two chicken IL-8 homologs. On a smaller scale ( $n=6$ strains), Larson et al. (2008) found the opposite effect. It is interesting to speculate that CXCLi2 (and not CXCLi1) may be the functional equivalent to IL-8 in humans. This is supported by structural data on amino acid similarity where CXCLi1 and CXCLi2 are 48 and 67\%, respectively, identical to human IL-8 (Sick et al., 2000; Gupta et al., 2008).

The three cellular responses defined by 'IL-8/CXCLi1/CXCLi2 production,' 'cellular toxicity', and 'Campylobacter invasion' are not always inextricably linked as demonstrated by the correlation curves (Figure 5). However, clear links were demonstrated between increased cytokine output (IL-8, CXCLil and 2) and 'toxicity' suggesting similar mechanisms of induction. Indeed, Hickey et al. $(1999,2000)$ suggested two mechanisms of Campylobacter-induced IL-8 production in human cells involving; (i) adherence and or invasion; and (ii) cdt expression. While this known link between IL-8 and invasion was demonstrated in INT407 human epithelial cells, we did not find a significant correlation between them in HT-29 cells. This was also the case for CXCLi2 production and invasion in avian cells. In contrast, a strong positive correlation was made in avian cells between CXCLi1 and invasion, again supporting an important role for these cytokines in early Campylobacter responses in chickens.

Numerous human cell lines have been used to study Campylobacter pathogenesis, including T84 (Zheng et al., 2008), INT407 (Borrmann et al., 2007), HT-29 (Bahrami et al., 2011), and CaCo-2 (Man et al., 2010) intestinal epithelial cells. There is very little data in avian intestinal cell systems. These cell lines are particularly useful for high throughput studies with many strains such as the current study. When considering the three cellular endpoints of IL-8 expression, cellular toxicity, and Campylobacter invasion none of these cells mimic equivalent in vivo responses exactly. Campylobacter invasion into $\mathrm{CaCo}-2$ cells show very good correlation to in vivo invasive potential in chickens (Hanel et al., 2004) and humans (Everest et al., 1992) but produce limited cytokine responses (MacCallum et al., 2006) whereas HT-29 and T84 produce robust cytokine responses but no good evidence of relevance to in vivo invasion responses (MacCallum et al., 2006). In our hands, we could detect cellular invasion in both HT-29 cells and the 8E11 avian cells at a level of $1-3 \%$ of the initial inoculum with sufficient robustness to differentiate strains and for consistency over three replicate experiments. Levels of invasion are particularly dependent on time and the starting inoculum, but our results are in keeping with levels of invasion of up to $4 \%$ in CaCo-2 cells shown previously (Hanel et al., 2004). This suggests great potential in the avian cell line used in this study for investigating the diversity of $C$. jejuni responses in vitro.

This study confirmed the importance of canonical pro- (ERK) and anti-inflammatory (PI 3-Kinase -Akt) pathways for the C. jejuni-induced production of IL-8 and IL-10 in human epithelial cells (Watson and Galan, 2005; Li et al., 2011). Furthermore, ERK-dependent Campylobacter invasion is also supported by previous studies (Jin et al., 2003; Hu et al., 2006;
Samuelson and Konkel, 2013; Samuelson et al., 2013). The importance of these pathways in avian cells is a novel result of this study and confirms that the underlying mechanisms are similar between human and chicken cells. In addition, the significantly higher IL-10 responses in the avian cells suggest that the avian gut may produce IL-10 as a method to tolerate large doses of Campylobacter and is supported by previous in vivo studies showing that some breeds of chicken produce more 'regulated' responses (Humphrey et al., 2014). While the avian cells used here are derived from leghorn chickens it would be interesting to speculate on the breeds used previously (Humphrey et al., 2014). There is evidence using Bayesian structural modeling of in vivo responses in chickens that IL-10 profiles are indeed different between breeds and this needs exploring further (Williams et al., 2013; Reid et al., 2016).

Study of Campylobacter uptake by endocytic pathways confirmed the requirement of lipid rafts (Lin et al., 2011) in human cells and extended this role to avian epithelial cells. We also found that microfilaments were required for invasion of both HT-29 cells and the avian ones. Interestingly, at least two mechanisms exist as INT407 (Konkel and Cieplak, 1992) and CaCo-2 (Russell and Blake, 1994) cells show microfilaments/microtubules-dependent and -independent mechanisms, respectively, suggesting that the role of cytoskeleton may be strongly cell dependent. Further work into mechanisms of uptake, in the present study, confirmed roles for dynamin and clathrin which has not been documented to date. Interestingly Cdt uptake into cells does involve clathrin coated pits (Thelestam and Frisan, 2004) and may be the mechanisms observed here. We could not confirm a consistent role for caveolins (using filipin and genistein) in the uptake process during this study. Indeed, this is consistent with a recent publication which suggests that $C$. jejuni invasion is independent of caveolins (Konkel et al., 2013).

One interesting consequence of inhibiting endocytic pathways was the concurrent reduction in cell toxicity confirming that Campylobacter is responsible for the toxicity and the endocytic inhibitors have negligible effects on cell viability. Another consequence of inhibiting endocytosis was the 'extra' effect of inhibiting cytokine production. Previously, De Zoete et al. (2010) established that live Campylobacter are very weak stimulators of both human and chicken TLR-2, -4 , and -5 . In striking contrast, lysed Campylobacter induce strong NF-kappaB activation through human TLR1/2/6 and TLR4 and chicken TLR2t2/16 and TLR4 but not via TLR5 of either species (De Zoete et al., 2010). Our results support the concept that 'invasion' or 'internalization' of some kind is necessary for cytokine production. Indeed, Hickey et al. (2000) also suggest an 'invasion' dependent pathway for IL-8 induction.

These results are novel because of the number and diversity of relevant C. jejuni strains used on an avian cell line to determine pathogenic mechanisms. However, we realize that there are certain limitations that provide an opportunity to improve our study in future work. Firstly, avian 8E11 cells are derived from small and large intestines of white leghorn chickens and are positive for enterocyte markers, villin, E-cadherin, and cytokeratin. Previous studies have confirmed the importance of broiler breed to the final inflammatory response and suggest 
that cells from commercial fast and slower growing breeds may be more relevant to study avian gut responses (Kaiser et al., 2016). Indeed, recent technologies point to the precision modeling of chicken intestinal slices (Punyadarsaniya et al., 2015). Secondly, with respect to assay methodology, we recognize that $6 \mathrm{~h}$ is probably not the optimal time to measure adhesion and earlier timepoints should be assessed in the future. In addition the gentamicin protection assay is subject to numerous limitations and artifacts as reviewed in detail previously (Friis et al., 2005). Finally, here we focused our attention on using C. jejuni strains that define the species, from a variety of sources and sequence types, as published previously (Sheppard et al., 2013). Recent Campylobacter outbreaks have highlighted the importance of invasion from the gut (e.g., to the liver) suggesting the importance of focussing on groups of invasive and non-invasive Campylobacter in future studies.

\section{CONCLUSION}

These novel data suggest that avian systems are likely to use similar host defense pathways to humans in response to Campylobacter spp. However, the sheer diversity and range of responses suggests that 'a one strain fits all approach' to in vivo experimental infection would not give meaningful data for the study of Campylobacter pathogenesis.

\section{AUTHOR CONTRIBUTIONS}

DJ was responsible for data generation and analysis across all figures of the manuscript. Design of signaling aspects of the work

\section{REFERENCES}

Akiyama, T., Ishida, J., Nakagawa, S., Ogawara, H., Watanabe, S., Itoh, N., et al. (1987). Genistein, a specific inhibitor of tyrosine-specific protein kinases. J. Biol. Chem. 262, 5592-5595.

Alessi, D. R., Cuenda, A., Cohen, P., Dudley, D. T., and Saltiel, A. R. (1995). PD 098059 is a specific inhibitor of the activation of mitogen-activated protein kinase kinase in vitro and in vivo. J. Biol. Chem. 270, 27489-27494. doi: 10.1074/jbc.270.46.27489

Bahrami, B., Macfarlane, S., and Macfarlane, G. T. (2011). Induction of cytokine formation by human intestinal bacteria in gut epithelial cell lines. J. Appl. Microbiol. 110, 353-363. doi: 10.1111/j.1365-2672.2010.04889.x

Bennett, W. E. Jr., González-Rivera, R., Puente, B. N., Shaikh, N., Stevens, H. J., Mooney, J. C., et al. (2010). Proinflammatory fecal mRNA and childhood bacterial enteric infections. Gut Microbes 1, 209-212. doi: 10.4161/gmic.1.4. 13004

Bonneau, L., Gerbeau-Pissot, P., Thomas, D., Der, C., Lherminier, J., Bourque, S., et al. (2010). Plasma membrane sterol complexation, generated by filipin, triggers signaling responses in tobacco cells. Biochim. Biophys. Acta 1798, 2150-2159. doi: 10.1016/j.bbamem.2010.07.026

Borrmann, E., Berndt, A., Hanel, I., and Kohler, H. (2007). Campylobacterinduced interleukin-8 responses in human intestinal epithelial cells and primary intestinal chick cells. Vet. Microbiol. 124, 115-124. doi: 10.1016/j.vetmic.2007. 04.041

Buelow, D. R., Christensen, J. E., Neal-Mckinney, J. M., and Konkel, M. E. (2011). Campylobacter jejuni survival within human epithelial cells is enhanced by the secreted protein CiaI. Mol. Microbiol. 80, 1296-1312. doi: 10.1111/j.1365-2958. 2011.07645.x was developed and overseen by VK. Design of invasion assays was lead by LW. TH and TW were responsible for re-drafting the work and revising it critically for important intellectual content. All authors approved the final submitted draft and had opportunity for editing the document.

\section{FUNDING}

The work was partially funded by a BBSRC grant awarded to TH (BB/M009610/1) and a bursary awarded by SUMS to DJ.

\section{ACKNOWLEDGMENTS}

The authors would like to thank Professor Samuel Sheppard (University of Bath) for the isolates used in this study and refer to previous publications on them (Sheppard et al., 2011, 2013).

\section{SUPPLEMENTARY MATERIAL}

The Supplementary Material for this article can be found online at: http://journal.frontiersin.org/article/10.3389/fmicb. 2017.01840/full\#supplementary-material

FIGURE S1 | The effect of methyl $\beta$-cytodextrin and cytochalasin D on Campylobacter invasion. (A) HT-29 and (B) 8E11 cells were treated with cytochalasin $D(5 \mu \mathrm{M})$ and methyl- $\beta$-cyclodextrin $(5 \mu \mathrm{M}) 30$ min prior to infection with $C$. jejuni $(n=31)$ for 6 h. Invasion was assessed with each dot representing three biological replicates in one strain. Results are also expressed as mean $\pm \mathrm{SD}$ of all strains measured. Differences were considered significant if $p \leq 0.05$.

Byrne, C. M., Clyne, M., and Bourke, B. (2007). Campylobacter jejuni adhere to and invade chicken intestinal epithelial cells in vitro. Microbiology 153, 561-569. doi: 10.1099/mic.0.2006/000711-0

Bæk, K. T., Vegge, C. S., and Brøndsted, L. (2011). HtrA chaperone activity contributes to host cell binding in Campylobacter jejuni. Gut Pathog. 3:13. doi: 10.1186/1757-4749-3-13

Chaloner, G., Wigley, P., Humphrey, S., Kemmett, K., Lacharme-Lora, L., Humphrey, T., et al. (2014). Dynamics of dual infection with Campylobacter jejuni strains in chickens reveals distinct strain-to-strain variation in infection ecology. Appl. Environ. Microbiol. 80, 6366-6372. doi: 10.1128/AEM. 01901-14

Chaussade, C., Rewcastle, G. W., Kendall, J. D., Denny, W. A., Cho, K., Gronning, L. M., et al. (2007). Evidence for functional redundancy of class IA PI3K isoforms in insulin signalling. Biochem. J. 404, 449-458. doi: 10.1042/ BJ20070003

Colin, D., Limagne, E., Jeanningros, S., Jacquel, A., Lizard, G., Athias, A., et al. (2011). Endocytosis of Resveratrol via lipid rafts and activation of downstream signaling pathways in cancer cells. Cancer Prev. Res. 4, 1095-1106. doi: 10.1158/ 1940-6207.CAPR-10-0274

Davis, L., and DiRita, V. (2008). Growth and laboratory maintenance of Campylobacter jejuni. Curr. Protoc. Microbiol. 34, 352-359.

De Zoete, M. R., Keestra, A. M., Roszczenko, P., and Van Putten, J. P. M. (2010). Activation of human and chicken toll-like receptors by Campylobacter spp. Infect. Immun. 78, 1229-1238. doi: 10.1128/IAI.00897-09

DEFRA (2012). Agriculture in the United Kingdom, in Government National Statistics. London: Department for Environment Food \& Rural Affairs.

Dugar, G., Herbig, A., Forstner, K. U., Heidrich, N., Reinhardt, R., Nieselt, K., et al. (2013). High-resolution transcriptome maps reveal strain-specific regulatory 
features of multiple Campylobacter jejuni isolates. PLOS Genet. 9:e1003495. doi: 10.1371/journal.pgen.1003495

Edwards, D. S., Milne, L. M., Morrow, K., Sheridan, P., Verlander, N. Q., Mulla, R., et al. (2014). Campylobacteriosis outbreak associated with consumption of undercooked chicken liver pâté in the East of England, September 2011: identification of a dose-response risk. Epidemiol. Infect. 142, 352-357. doi: $10.1017 /$ S0950268813001222

Eucker, T. P., and Konkel, M. E. (2012). The cooperative action of bacterial fibronectin-binding proteins and secreted proteins promote maximal Campylobacter jejuni invasion of host cells by stimulating membrane ruffling. Cell. Microbiol. 14, 226-238. doi: 10.1111/j.1462-5822.2011.01714.x

Everest, P. H., Goossens, H., Butzler, J. P., Lloyd, D., Knutton, S., Ketley, J. M., et al. (1992). Differentiated Caco-2 cells as a model for enteric invasion by Campylobacter jejuni and C. coli. J. Med. Microbiol. 37, 319-325. doi: 10.1099/ 00222615-37-5-319

Fernandez de Mattos, S., Villalonga, P., Clardy, J., and Lam, E. (2008). FOXO3a mediates the cytotoxic effects of cisplatin in colon cancer. Mol. Cancer Ther. 7, 3237-3246. doi: 10.1158/1535-7163.MCT-08-0398

Friis, L. M., Keelan, M., and Taylor, D. E. (2009). Campylobacter jejuni drives MyD88-independent interleukin-6 secretion via toll-like receptor 2. Infect. Immun. 77, 1553-1560. doi: 10.1128/IAI.00707-08

Friis, L. M., Pin, C., Pearson, B. M., and Wells, J. M. (2005). In vitro cell culture methods for investigating Campylobacter invasion mechanisms. J. Microbiol. Methods 61, 145-160. doi: 10.1016/j.mimet.2004.12.003

Goddette, D. W., and Frieden, C. (1986). The kinetics of cytochalasin D binding to monomeric actin. J. Biol. Chem. 261, 15970-15973.

Guerry, P. (2007). Campylobacter flagella: not just for motility. Trends Microbiol. 15, 456-461. doi: 10.1016/j.tim.2007.09.006

Gupta, R. S., Hillier, L. W., Miller, W., Birney, E., Warren, W., Hardison, R. C., et al. (2008). Re-evaluation of chicken CXCR1 determines the true gene structure: CXCLi1 (K60) and CXCLi2 (CAF/interleukin-8) are ligands for this receptor. J. Biol. Chem. 283, 16408-16415. doi: 10.1074/jbc.M800998200

Hanel, I., Muller, J., Muller, W., and Schulze, F. (2004). Correlation between invasion of Caco-2 eukaryotic cells and colonization ability in the chick gut in Campylobacter jejuni. Vet. Microbiol. 101, 75-82. doi: 10.1016/j.vetmic.2004. 04.004

Harrison, D., Corry, J. E. L., Tchórzewska, M. A., Morris, V. K., and Hutchison, M. L. (2013). Freezing as an intervention to reduce the numbers of campylobacters isolated from chicken livers. Lett. Appl. Microbiol. 57, 206-213. doi: 10.1111/lam.12098

Hickey, T. E., Baqar, S., Bourgeois, A. L., Ewing, C. P., and Guerry, P. (1999). Campylobacter jejuni-stimulated secretion of interleukin-8 by INT407 cells. Infect. Immun. 67, 88-93.

Hickey, T. E., McVeigh, A. L., Scott, D. A., Michielutti, R. E., Bixby, A., Carroll, S. A., et al. (2000). Campylobacter jejuni cytolethal distending toxin mediates release of interleukin-8 from intestinal epithelial cells. Infect. Immun. 68, 6535-6541. doi: 10.1128/IAI.68.12.6535-6541.2000

Hu, L., Bray, M. D., Osorio, M., and Kopecko, D. J. (2006). Campylobacter jejuni induces maturation and cytokine production in human dendritic cells. Infect. Immun. 74, 2697-2705. doi: 10.1128/IAI.74.5.2697-2705.2006

Humphrey, S., Chaloner, G., Kemmett, K., Davidson, N., Williams, N., Kipar, A., et al. (2014). Campylobacter jejuni is not merely a commensal in commercial broiler chickens and affects bird welfare. MBio 5, 1-7. doi: 10.1128/mBio. 01364-14

Humphrey, S., Lacharme-Lora, L., Chaloner, G., Gibbs, K., Humphrey, T., Williams, N., et al. (2015). Heterogeneity in the infection biology of Campylobacter jejuni isolates in three infection models reveals an invasive and virulent phenotype in a ST21 isolate from poultry. PLOS ONE 10:e0141182. doi: 10.1371/journal.pone.0141182

Jennings, J. L., Sait, L. C., Perrett, C. A., Foster, C., Williams, L. K., Humphrey, T. J., et al. (2011). Campylobacter jejuni is associated with, but not sufficient to cause vibrionic hepatitis in chickens. Vet. Microbiol. 149, 193-199. doi: 10.1016/j.vetmic.2010.11.005

Jin, S., Song, Y. C., Emili, A., Sherman, P. M., and Chan, V. L. (2003). JlpA of Campylobacter jejuni interacts with surface-exposed heat shock protein $90 \alpha$ and triggers signalling pathways leading to the activation of NF- $\mathrm{KB}$ and p38 MAP kinase in epithelial cells. Cell. Microbiol. 5, 165-174. doi: 10.1046/j.1462-5822. 2003.00265.x
Kaiser, A., Willer, T., Sid, H., Petersen, H., Baumgärtner, W., Steinberg, P., et al. (2016). Susceptibility of primary chicken intestinal epithelial cells for low pathogenic avian influenza virus and velogenic viscerotropic Newcastle disease virus. Virus Res. 225, 50-63. doi: 10.1016/j.virusres.2016.09.001

Karst, A. M., Dai, D. L., Cheng, J. Q., and Li, G. (2006). Role of p53 up-regulated modulator of apoptosis and phosphorylated Akt in melanoma cell growth, apoptosis, and patient survival. Cancer Res. 66, 9221-9226. doi: 10.1158/00085472.CAN-05-3633

Konkel, M. E., and Cieplak, W. (1992). Altered synthetic response of Campylobacter jejuni to cocultivation with human epithelial cells is associated with enhanced internalization. Infect. Immun. 60, 4945-4949.

Konkel, M. E., Klena, J. D., Rivera-amill, V., Monteville, M. R., Biswas, D., Raphael, B., et al. (2004). Secretion of virulence proteins from Campylobacter jejuni is dependent on a functional flagellar export apparatus. J. Bacteriol. 186, 3296-3303. doi: 10.1128/JB.186.11.3296

Konkel, M. E., Samuelson, D. R., Eucker, T. P., Shelden, E. A., and O'Loughlin, J. L. (2013). Invasion of epithelial cells by Campylobacter jejuni is independent of caveolae. Cell Commun. Signal. 11:100. doi: 10.1186/1478-811X-11-100

Larson, C. L., Shah, D. H., Dhillon, A. S., Call, D. R., Ahn, S., Haldorson, G. J., et al. (2008). Campylobacter jejuni invade chicken LMH cells inefficiently and stimulate differential expression of the chicken CXCLi1 and CXCLi2 cytokines. Microbiology 154, 3835-3847. doi: 10.1099/mic.0.2008/021279-0

Lee, M. S., Johansen, L., Zhang, Y., Wilson, A., Keegan, M., Avery, W., et al. (2007). The novel combination of chlorpromazine and pentamidine exerts synergistic antiproliferative effects through dual mitotic action. Cancer Res. 67, 11359-11367. doi: 10.1158/0008-5472.CAN-07-2235

Lee, R. B., Hassane, D. C., Cottle, D. L., Pickett, L., and Pickett, C. L. (2003). Interactions of Campylobacter jejuni cytolethal distending toxin subunits CdtA and CdtC with HeLa cells. Infect. Immun. 71, 4883-4890. doi: 10.1128/IAI.71.9. 4883

Li, W. W., Lin, S., Li, W. W., Wang, W., Li, X., and Xu, D. (2016). IL-8 interacts with metadherin promoting proliferation and migration in gastric cancer. Biochem. Biophys. Res. Commun. 478, 1330-1337. doi: 10.1016/j.bbrc.2016.08.123

Li, Y.-P., Vegge, C. S., Brøndsted, L., Madsen, M., Ingmer, H., and Bang, D. D. (2011). Campylobacter jejuni induces an anti-inflammatory response in human intestinal epithelial cells through activation of phosphatidylinositol 3-kinase/Akt pathway. Vet. Microbiol. 148, 75-83. doi: 10.1016/j.vetmic.2010. 08.009

Lin, C. D., Lai, C. K., Lin, Y. H., Hsieh, J. T., Sing, Y. T., Chang, Y. C., et al. (2011). Cholesterol depletion reduces entry of Campylobacter jejuni cytolethal distending toxin and attenuates intoxication of host cells. Infect. Immun. 79, 3563-3575. doi: 10.1128/IAI.05175-11

Livak, K. J., and Schmittgen, T. D. (2001). Analysis of relative gene expression data using real-time quantitative PCR and. Methods 25, 402-408. doi: 10.1006/meth. 2001.1262

MacCallum, A. J., Harris, D., Haddock, G., and Everest, P. H. (2006). Campylobacter jejuni-infected human epithelial cell lines vary in their ability to secrete interleukin-8 compared to in vitro-infected primary human intestinal tissue. Microbiology 152, 3661-3665. doi: 10.1099/mic.0.29234-0

Macia, E., Ehrlich, M., Massol, R., Boucrot, E., Brunner, C., and Kirchhausen, T. (2006). Dynasore, a cell-permeable inhibitor of dynamin. Dev. Cell 10, 839-850. doi: 10.1016/j.devcel.2006.04.002

Man, S. M., Kaakoush, N. O., Leach, S. T., Nahidi, L., Lu, H. K., Norman, J., et al. (2010). Host attachment, invasion, and stimulation of proinflammatory cytokines by Campylobacter concisus and other non-Campylobacter jejuni Campylobacter species. J. Infect. Dis. 202, 1855-1865. doi: 10.1086/657316

Neill, S. D., Campbell, J. N., and Greene, J. A. (1984). Campylobacter species in broiler chickens. Avian Pathol. 13, 777-785. doi: 10.1080/03079458408418574

Oelschlaeger, T. A., Guerry, P., and Kopecko, D. J. (1993). Unusual microtubuledependent endocytosis mechanisms triggered by Campylobacter jejuni and Citrobacter freundii. Proc. Natl. Acad. Sci. U.S.A. 90, 6884-6888. doi: 10.1073/ pnas.90.14.6884

Page, A. J., Cummins, C. A., Hunt, M., Wong, V. K., Reuter, S., Holden, M. T. G., et al. (2015). Roary: rapid large-scale prokaryote pan genome analysis. Bioinformatics 31, 3691-3693. doi: 10.1093/bioinformatics/btv421

Parkhill, J., Wren, B. W., Mungall, K., Ketley, J. M., Churcher, C., Basham, D., et al. (2000). The genome sequence of the food-borne pathogen Campylobacter jejuni reveals hypervariable sequences. Nature 403, 665-668. doi: 10.1038/35001088 
Pascoe, B., Méric, G., Murray, S., Yahara, K., Mageiros, L., Bowen, R., et al. (2015). Enhanced biofilm formation and multi-host transmission evolve from divergent genetic backgrounds in Campylobacter jejuni. Environ. Microbiol. 17, 4779-4789. doi: 10.1111/1462-2920.13051

Pickett, C. L., Pesci, E. C., Cottle, D. L., Russell, G., and Erdem, A. N. (1996). Prevalence of cytolethal distending toxin production in Campylobacter jejuni and relatedness of Campylobacter sp. cdtB gene. Infect. Immun. 64, 2070-2078.

Punyadarsaniya, D., Winter, C., Mork, A. K., Amiri, M., Naim, H. Y., Rautenschlein, S., et al. (2015). Precision-cut intestinal slices as a culture system to analyze the infection of differentiated intestinal epithelial cells by avian influenza viruses. J. Virol. Methods 212, 71-75. doi: 10.1016/j. jviromet.2014.10.015

Reid, W. D. K., Close, A. J., Humphrey, S., Chaloner, G., Lacharme-Lora, L., Rothwell, L., et al. (2016). Cytokine responses in birds challenged with the human food-borne pathogen Campylobacter jejuni implies a Th17 response. R. Soc. Open Sci. 3:150541. doi: 10.1098/rsos.150541

Rivera-Amill, V., Kim, B. J., Seshu, J., and Konkel, M. E. (2001). Secretion of the virulence-associated Campylobacter invasion antigens from Campylobacter jejuni requires a stimulatory signal. J. Infect. Dis. 183, 1607-1616. doi: 10.1086/ 320704

Rodal, S. K., Skretting, G., Garred, O., Vilhardt, F., van Deurs, B., and Sandvig, K. (1999). Extraction of cholesterol with methyl-beta -cyclodextrin perturbs formation of clathrin-coated endocytic vesicles. Mol. Biol. Cell 10, 961-974. doi: $10.1091 / \mathrm{mbc} \cdot 10.4 .961$

Russell, R. G., and Blake, D. C. (1994). Cell association and invasion of Caco-2 cells by Campylobacter jejuni. Infect. Immun. 62, 3773-3779.

Samuelson, D. R., Eucker, T. P., Bell, J. A., Dybas, L., Mansfield, L. S., and Konkel, M. E. (2013). The Campylobacter jejuni CiaD effector protein activates MAP kinase signaling pathways and is required for the development of disease. Cell Commun. Signal. 11:79. doi: 10.1186/1478-811X-11-79

Samuelson, D. R., and Konkel, M. E. (2013). Serine phosphorylation of cortactin is required for maximal host cell invasion by Campylobacter jejuni. Cell Commun. Signal. 11:82. doi: 10.1186/1478-811X-11-82

Seemann, T. (2014). Prokka: rapid prokaryotic genome annotation. Bioinformatics 30, 2068-2069. doi: 10.1093/bioinformatics/btu153

Sheppard, S. K., Colles, F. M., McCarthy, N. D., Strachan, N. J. C., Ogden, I. D., Forbes, K. J., et al. (2011). Niche segregation and genetic structure of Campylobacter jejuni populations from wild and agricultural host species. Mol. Ecol. 20, 3484-3490. doi: 10.1111/j.1365-294X.2011.05179.x

Sheppard, S. K., Didelot, X., Meric, G., Torralbo, A., Jolley, K. A., Kelly, D. J., et al. (2013). Genome-wide association study identi fi es vitamin B 5 biosynthesis as a host speci fi city factor in Campylobacter. Proc. Natl. Acad. Sci. U.S.A. 110, 1-5. doi: $10.5061 /$ dryad.28n 35

Sick, C., Schneider, K., Staeheli, P., and Weining, K. C. (2000). Novel chicken CXC and CC chemokines. Cytokine 12, 181-186. doi: 10.1006/cyto.1999.0543

Silva, J., Leite, D., Fernandes, M., Mena, C., Gibbs, P. A., and Teixeira, P. (2011). Campylobacter spp. As a foodborne pathogen: a review. Front. Microbiol. 2:200. doi: $10.3389 /$ fmicb. 2011.00200
Tamura, K., Stecher, G., Peterson, D., Filipski, A., and Kumar, S. (2013). MEGA6: Molecular evolutionary genetics analysis version 6.0. Mol. Biol. Evol. 30, 2725-2729. doi: 10.1093/molbev/mst197

Thelestam, M., and Frisan, T. (2004). Cytolethal distending toxins. Rev. Physiol. Biochem. Pharmacol. 152, 111-133. doi: 10.1007/s10254-004-0030-8

Watson, R. O., and Galan, J. E. (2005). Signal transduction in Campylobacter jejuniinduced cytokine production. Cell Microbiol. 7, 655-665. doi: 10.1111/j.14625822.2004.00498.x

Watson, R. O., and Galán, J. E. (2008). Campylobacter jejuni survives within epithelial cells by avoiding delivery to lysosomes. PLOS Pathog. 4:e14. doi: 10.1371/journal.ppat.0040014

Weflen, A., Alto, N., Viswanathan, V., and Hecht, G. (2010). E. coli secreted protein F promotes EPEC invasion of intestinal epithelial cells via an SNX9dependent mechanism. Cell. Microbiol. 12, 919-929. doi: 10.1007/s12020-0099266-z.A

Wells, C. L., Jechorek, R. P., Kinneberg, K. M., Debol, S. M., and Erlandsen, S. L. (1999). The isoflavone genistein inhibits internalization of enteric bacteria by cultured Caco-2 and HT-29 enterocytes. J. Nutr. 129, 634-640.

Wells, C. L., Van De Westerlo, E. M. A., Jechorek, R. P., Haines, H. M., and Erlandsen, S. L. (1998). Cytochalasin-induced actin disruption of polarized enterocytes can augment internalization of bacteria. Infect. Immun. 66, 2410-2419.

Williams, L. K., Sait, L. C., Trantham, E. K., Cogan, T. A., and Humphrey, T. J. (2013). Campylobacter infection has different outcomes in fast- and slowgrowing broiler chickens. Avian Dis. 57, 238-241. doi: 10.1637/10442-110212Reg.1

Wooldridge, K. G., Williams, P. H., and Ketley, J. M. (1996). Host signal transduction and endocytosis of Campylobacter jejuni. Microb. Pathog. 21, 299-305. doi: 10.1006/mpat.1996.0063

Zheng, J., Meng, J., Zhao, S., Singh, R., and Song, W. (2008). Campylobacterinduced interleukin-8 secretion in polarized human intestinal epithelial cells requires Campylobacter-secreted cytolethal distending toxin- and tolllike receptor-mediated activation of NF-кB. Infect. Immun. 76, 4498-4508. doi: 10.1128/IAI.01317-07

Conflict of Interest Statement: The authors declare that the research was conducted in the absence of any commercial or financial relationships that could be construed as a potential conflict of interest.

The reviewer PN and handling Editor declared their shared affiliation.

Copyright (c) 2017 John, Williams, Kanamarlapudi, Humphrey and Wilkinson. This is an open-access article distributed under the terms of the Creative Commons Attribution License (CC BY). The use, distribution or reproduction in other forums is permitted, provided the original author(s) or licensor are credited and that the original publication in this journal is cited, in accordance with accepted academic practice. No use, distribution or reproduction is permitted which does not comply with these terms. 